\title{
Planning energy retrofits of historic buildings
}

\section{EN16883:2017 in practice}

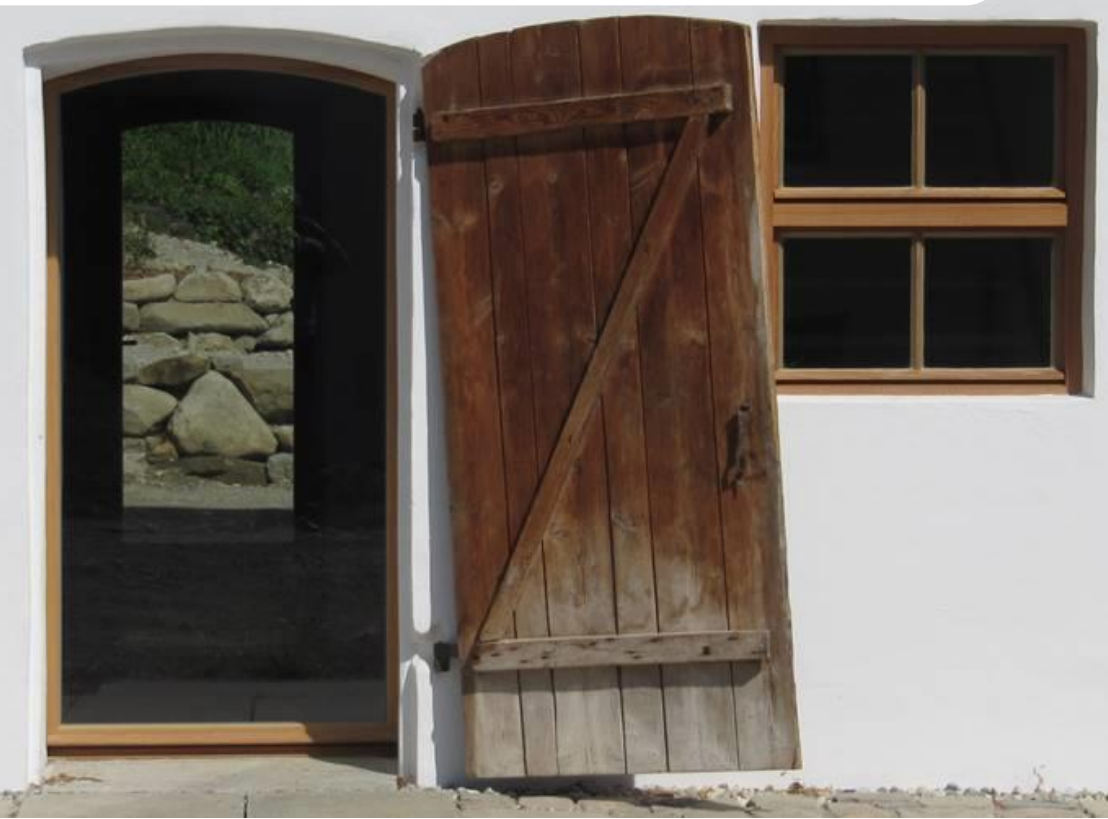

IEA SHC TASK 59 | EBC Annex 76 Renovating Historic Buildings Towards Zero Energy 


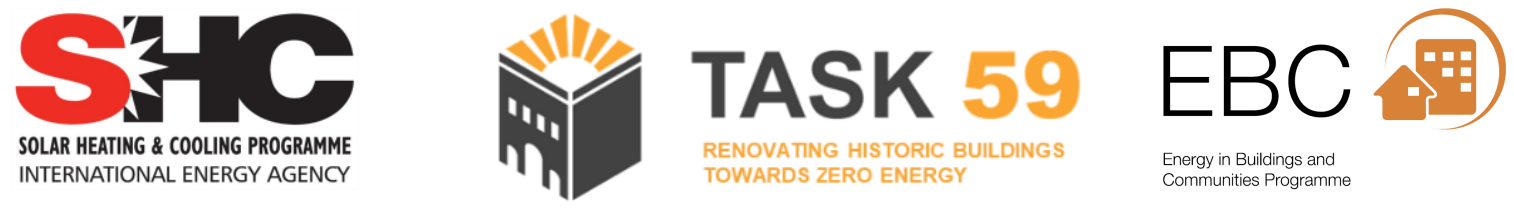

\section{Planning \\ energy retrofits of \\ historic buildings}

\section{EN16883:2017 in practice}

\section{Editor:}

\section{Gustaf Leijonhufvud,}

Contributing authors:

Tor Broström, Alessia Buda, Daniel Herrera, Franziska Haas, Alexandra Troi, Dagmar Exner, Sara Mauri, Ernst Jan de Place Hansen, Valentina Marincioni, Nathalie Vernimme

\section{October 2021}

SHC Task 59 | EBC Annex 76 | Report D.B3

DOI: 10.18777/ieashc-task59-2021-0003

Cover Photo @ Reinhard Lindner

The contents of this report do not necessarily reflect the viewpoints or policies of the International Energy Agency (IEA) or its member countries, the IEA Solar Heating and Cooling Technology Collaboration Programme (SHC TCP) members or the participating researchers. 


\section{IEA SHC Task 59 | EBC Annex 76: Deep renovation of historic buildings towards lowest possible energy demand and $\mathrm{CO}_{2}$ emission (NZEB)}

\section{Solar Heating and Cooling Technology Collaboration Programme (IEA SHC)}

The Solar Heating and Cooling Technology Collaboration Programme was founded in 1977 as one of the first multilateral technology initiatives ("Implementing Agreements") of the International Energy Agency.

Our mission is "Through multi-disciplinary international collaborative research and knowledge exchange, as well as market and policy recommendations, the IEA SHC will work to increase the deployment rate of solar heating and cooling systems by breaking down the technical and non-technical barriers."

IEA SHC members carry out cooperative research, development, demonstrations, and exchanges of information through Tasks (projects) on solar heating and cooling components and systems and their application to advance the deployment and research and development activities in the field of solar heating and cooling.

Our focus areas, with the associated Tasks in parenthesis, include:

- Solar Space Heating and Water Heating (Tasks 14, 19, 26, 44, 54)

- Solar Cooling (Tasks 25, 38, 48, 53, 65)

- Solar Heat for Industrial and Agricultural Processes (Tasks 29, 33, 49, 62, 64)

- Solar District Heating (Tasks 7, 45, 55)

- Solar Buildings/Architecture/Urban Planning (Tasks 8, 11, 12, 13, 20, 22, 23, 28, 37, 40, 41, 47, 51, 52, 56, $59,63,66)$

- $\quad$ Solar Thermal \& PV (Tasks 16, 35, 60)

- Daylighting/Lighting (Tasks 21, 31, 50,61)

- $\quad$ Materials/Components for Solar Heating and Cooling (Tasks 2, 3, 6, 10, 18, 27, 39)

- Standards, Certification, and Test Methods (Tasks 14, 24, 34, 43, 57)

- $\quad$ Resource Assessment (Tasks 1, 4, 5, 9, 17, 36, 46)

- $\quad$ Storage of Solar Heat (Tasks 7, 32, 42, 58, 67)

In addition to our Task work, other activities of the IEA SHC include our:

$>$ SHC Solar Academy

$>$ Solar Heat Worldwide, annual statics report

$>$ SHC International Conference

Our members

$\begin{array}{lll}\text { Australia } & \text { European Copper Institute } & \text { SICREEE } \\ \text { Austria } & \text { France } & \text { Slovakia } \\ \text { Belgium } & \text { Germany } & \text { South Africa } \\ \text { Canada } & \text { International Solar Energy Society } & \text { Spain } \\ \text { CCREEE } & \text { Italy } & \text { Sweden } \\ \text { China } & \text { Netherlands } & \text { Switzerland } \\ \text { Denmark } & \text { Norway } & \text { Turkey } \\ \text { EACREEE } & \text { Portugal } & \text { United Kingdom } \\ \text { ECREEE } & \text { RCREEE } & \\ \text { European Commission } & \text { SACREEE } & \end{array}$

For more information on the IEA SHC work, including many free publications, please visit www.iea-shc.org.

\section{Energy in Buildings and Communities Technology Collaboration Programme (IEA EBC)}

To reach the objectives of SHC Task 59 the IEA SHC implementing Agreement has collaborated with the IEA EBC Implementing Agreement at a "Medium Level Collaboration", and with the IEA PVPS Implementing Agreement at a "Minimum Level Collaboration" as outlined in the SHC Implementing Agreement's Policy on Collaboration 


\section{Contents}

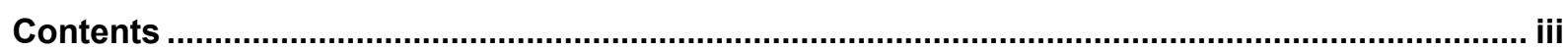

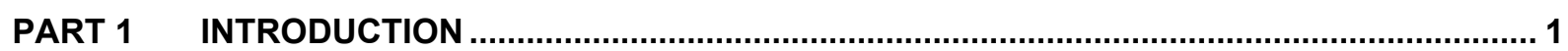

1.1 Scope

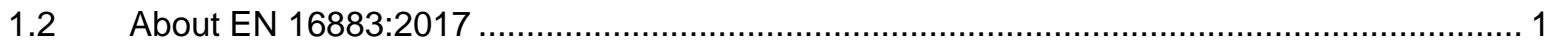

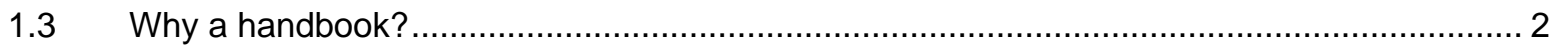

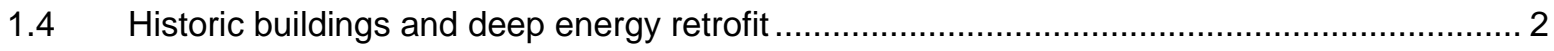

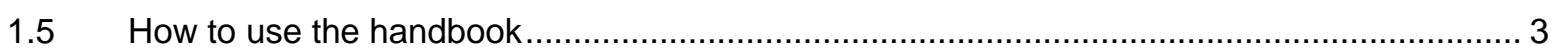

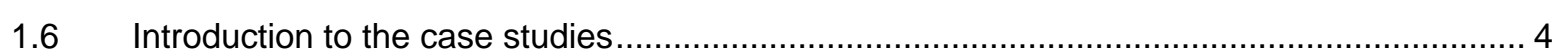

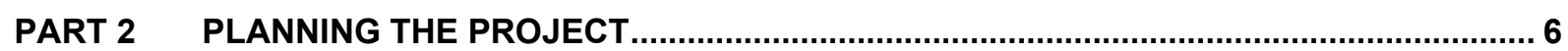

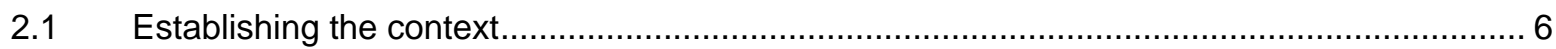

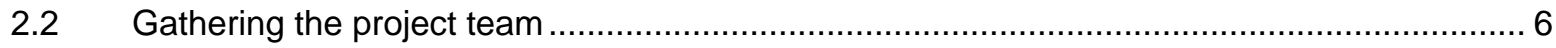

2.3 Assigning responsibilities and lines of communication ................................................. 7

$2.4 \quad$ Integration with existing work processes and standards ................................................. 9

$2.5 \quad$ Working with stocks, districts and communal solutions................................................. 9

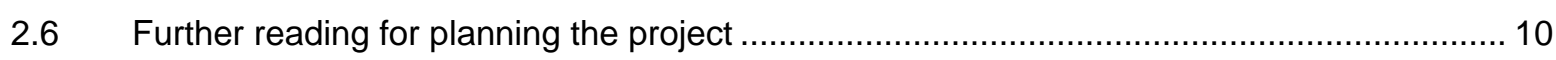

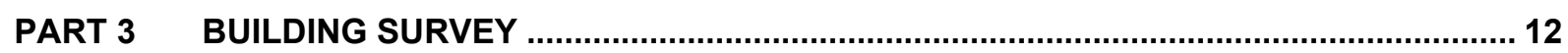

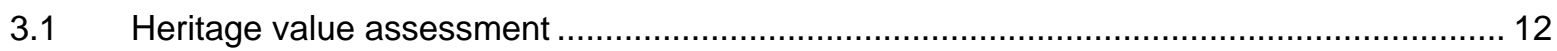

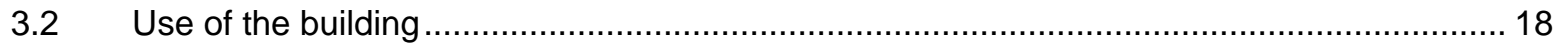

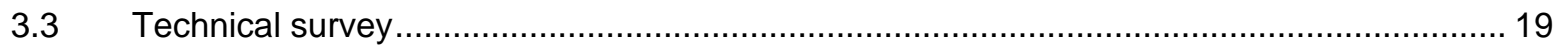

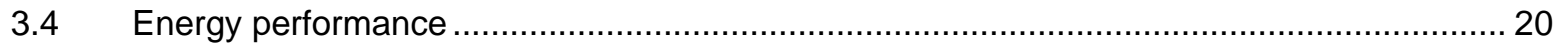

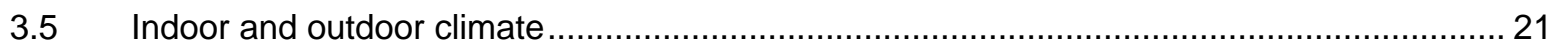

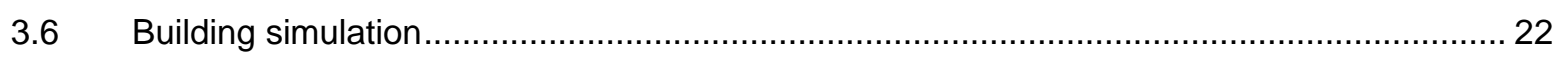

PART 4 SETTING THE OBJECTIVES AND THE ASSESSMENT CRITERIA ............................. 25

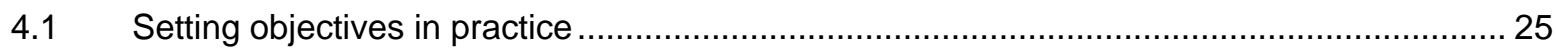

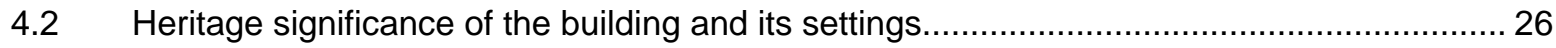

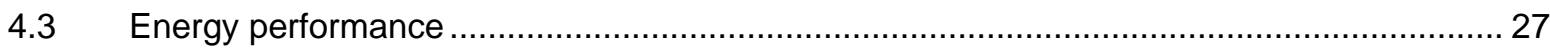

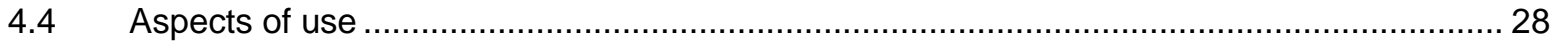

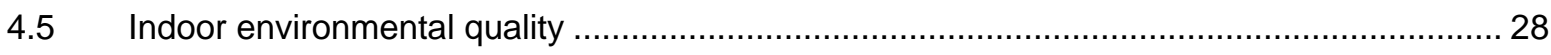

4.6 Technical compatibility with the existing structural, constructional, technical systems......... 29

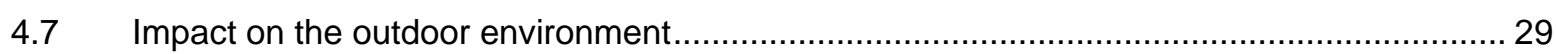

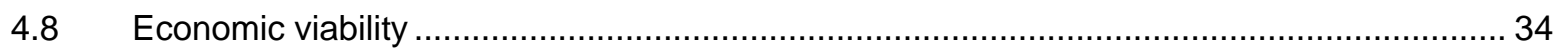

PART 5 SELECTING MEASURES

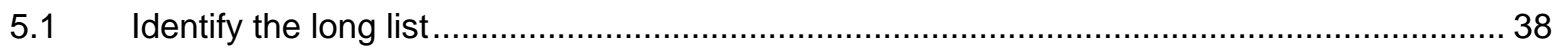

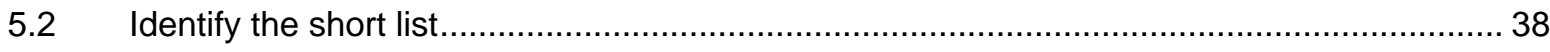

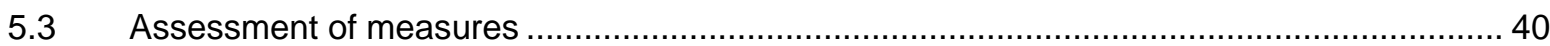




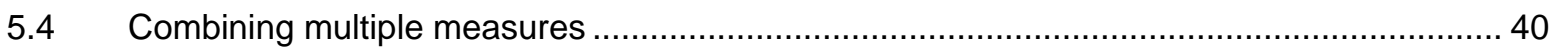

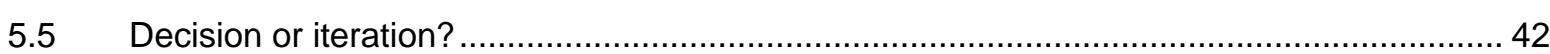

PART 6 IMPLEMENTATION, DOCUMENTATION AND EVALUATION..................................... 43

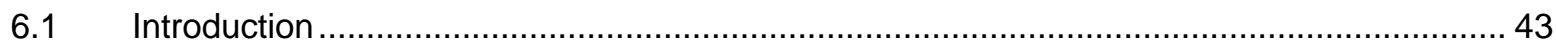

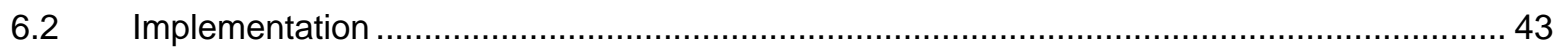

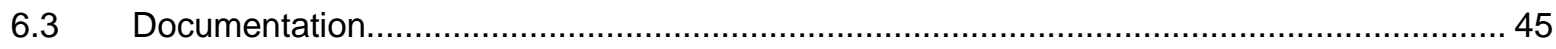

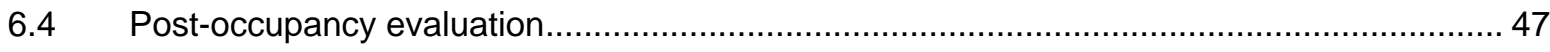

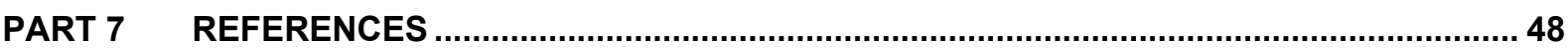

This handbook follows the systematic approach outlined by the European standard EN 16883:2017 Guidelines for improving the energy performance of historic buildings. It describes how the standard can be applied in practice with chapters on heritage value assessment, building survey and holistic assessment of energy efficiency measures. The book draws on the experience from a team of international leading experts in the field of energy efficiency in historic buildings.

The intended audience for the handbook is professionals working with the refurbishment of existing buildings: architects, engineers, heritage consultants, building surveyors and professional property owners. It points at the possibilities to lower the energy use in existing buildings without compromising their heritage values, and provides practical guidance on how to identify, assess and select energy retrofit measures through a multidisciplinary planning process.

Throughout the book you will follow case studies that illustrate how the different stages of the planning process can be carried out in practice. The text is accompanied by best practice examples, illustrations and links to written and online resources. 


\section{PART 1 INTRODUCTION}

\subsection{Scope}

This handbook supports professionals involved in the energy retrofit of historic buildings. It takes a practical approach to the subject, based on the experience of leading international experts in the field. It follows the structure and overall ideas advocated by the European standard EN 16883:2017 Conservation of cultural heritage Guidelines for improving the energy performance of historic buildings (European Committee for Standardization, 2017), but it should not be used as a substitute to the standard. To comply with the standard this book will not be sufficient.

The terminology regarding the alteration of historic buildings often leads to mild confusion, and the terms are not always possible to directly translate between different languages. For the purpose of this book, a few often used terms are defined in the following way: Energy retrofit includes all energy efficiency measures that aim to increase the energy efficiency, and/or reduce the carbon footprint of the building. If two or more such measures are combined, they are together called a package of energy efficiency measures. Energy efficiency measures are understood in a broad sense, and they can affect:

- The building envelope (e.g. added insulation)

- The heating, ventilation and airconditioning (HVAC) system (e.g. ftxventilation)

- The use of the building (e.g. heating only parts of the building)

- The energy source (e.g. replacing natural gas boiler with geo thermal heat pump)

- The microgeneration of energy (e.g. PVpanels with battery storage)

Energy retrofits are often part of other alterations to whole, or parts, of buildings. Such changes are given different labels depending on the context, for example restoration, renovation or refurbishment. These, and other similar terms have slightly different meanings in different countries and cultural spheres, and will not be defined here (see EN 15898 Conservation of cultural property-Main general terms and definitions (European Committee for Standardization, 2011)) The important message here is that energy retrofits often are made in conjunction with other alterations of the building, and the planning has to be integrated.

Historic buildings are defined as all buildings having cultural heritage values, which encompasses also non-listed buildings. For a discussion, see section $\mathrm{xx}$ below.

The book is focused on the planning process. It gives guidance on how to set up a structured process. The book will not provide universal answers about which energy efficiency measure to choose under specific conditions, or describe in detail how measures can be assessed. Many aspects covered in this book require years of training and experience to master. If there is a need to do, for example, an in-depth hygrothermal assessment, then there is a need to consult an expert in that field. However, the book will inspire by showing best practice examples, and give general guidance about all the steps in the interdisciplinary planning process.

\subsection{About EN 16883:2017}

EN 16883:2017 Conservation of cultural heritage - Guidelines for improving the energy performance of historic buildings is a European standard. The standard is useful for facilitating decisions about the balance between energy performance, use, and heritage preservation. It is applicable to all kinds of buildings, as it is more focused on a systematic decision process than on specific outcomes. In essence, the standard presents a generic procedure for decision-making, with the aim to facilitate the best decision in each individual case.

The planning process advocated by the standard is based on basic structured decision- 
making: establish the decision context, define objectives, develop alternatives, assess consequences and select the best trade-off. The first step is to make a thorough interdisciplinary investigation of the current status of the building and the prerequisities for the project (Where are we?). The second step is to define the objectives of the project (Where do we want to go?), and the final step is to identify and assess energy efficiency measures and to select those that meet the objectives (How do we get there?). It is important to point out that this process isn't always linear. For example, sometimes it is impossible to find measures that fulfil the objectives - then there is a need to take a step back and revise the objectives.

\subsection{Why a handbook?}

An evaluation of EN 16883:2017 carried out within the IEA SHC Task 59 project Renovating historic buildings toward zero energy showed that the standard was appreciated by the research community and experts, but that potential users had difficulties in understanding how to apply the standard in practice. An overarching observation was that the standard, as a standalone document, is neither sufficient to convince decision-makers about the benefits of its use, nor self-explanatory for the majority of new users. Complementary, and easily accessible, information is needed to support adopters. Such information would consist of:

- Examples of how the steps in the standard can be carried out

- Example of how the standard can be integrated with existing standards and procedures

- Examples of energy retrofits and energy efficiency measures

- Examples showing the benefit of following the standard

- Resources, literature and tools supplementing the steps in the standard

\subsection{Historic buildings and deep energy retrofit}

In this book we use the same definition of historic buildings as in EN 16883:2017: "a building of heritage significance". Heritage significance is understood as the combination of all the heritage values assigned to the building and its setting. This does not require that the building is officially designated as heritage. It can be any building with heritage values. This definition is deviating from what we normally see in policy making and legislation, where only officially designated buildings are regarded as heritage buildings. This less black-and-white understanding of what constitutes a historic building implies that preservation aspects should be taken into account for many not formally listed buildings, but also that there is a potential to introduce energy efficiency measures in buildings with the highest level of protection.
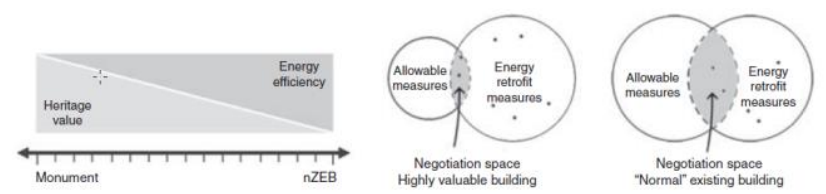

Fig.x Traditional approach of heritage conservation vs energy efficiency (left) and lowest possible energy demand as a negotiation space as proposed by Herrera-Avellanosa et al (2019).

A very good question is what target level, in terms of energy performance, that is plausible to have for historic buildings. In today's regulations on energy performance of buildings it is common to set a near zero energy use target for new and renovated buildings, but such a low target is unrealistic for many (but not all) historic buildings. Instead of recommending specific targets or levels, we advocate an "as low as possible" approach. What is possible (or acceptable) has to be decided in each project through a compromise between competing interests/parties (see the illustration of this "negotiation space" in fig $\mathrm{x}$ ). Often, there are low-hanging fruits that everyone can agree on (i.e. highly energy-efficient measures with low impact on heritage values), and a number of higher-hanging fruits where it is difficult to 
decide if the benefits surpass the risks. Experience tells us that it is important to identify and agree on the former ones, and not let infected discussions about the latter ones obstruct the whole project - don't let the perfect be the enemy of the good. For more elaborate discussions of historic buildings and energy efficiency, see Herrera-Avellanosa et al (2019) and Webb (2017).

\subsection{How to use the handbook}

The handbook largely follows the framework suggested in EN 16883:2017 (with a few exceptions) in order to explain and clarify how the different steps of the standard can be carried out in practice. The handbook has a value in itself as it contains common approaches to planning, but it is meant to be used in tandem with the standard.

The main text gives an overview of the different steps, and tries to give a balanced account of the most essential aspects of each step. The idea is not to describe in detail how the step shall be carried out, but to create a common language and a common roadmap for an interdisciplinary professional group.

In addition to the main text there are text boxes and illustrations providing complementary information. Success factors for different planning steps are found in green text boxes. Checklists, consisting of items that are recommended for all projects (black text colour), and for some but not all projects (grey text colour) are found in orange boxes.

Best practice examples of energy retrofit of historic buildings are accompanying the main text. There are best practice examples of both comprehensive refurbishment projects of whole historic buildings as well as of individual measures. The cases are a selection of examples from the Hiberatlas and the HiBERtool online resources, and the intention is to inspire the reader to access these and other online resources.

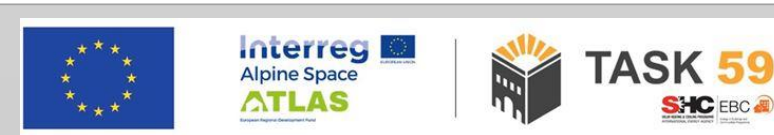

HiBERatlas - Historic Building Energy Retrofit Atlas

The HiBERatlas is a best-practice database of exemplary energy efficient interventions in historic buildings presents best-practice examples of how historic buildings can be renovated to achieve high levels of energy efficiency while respecting and protecting its heritage significance.

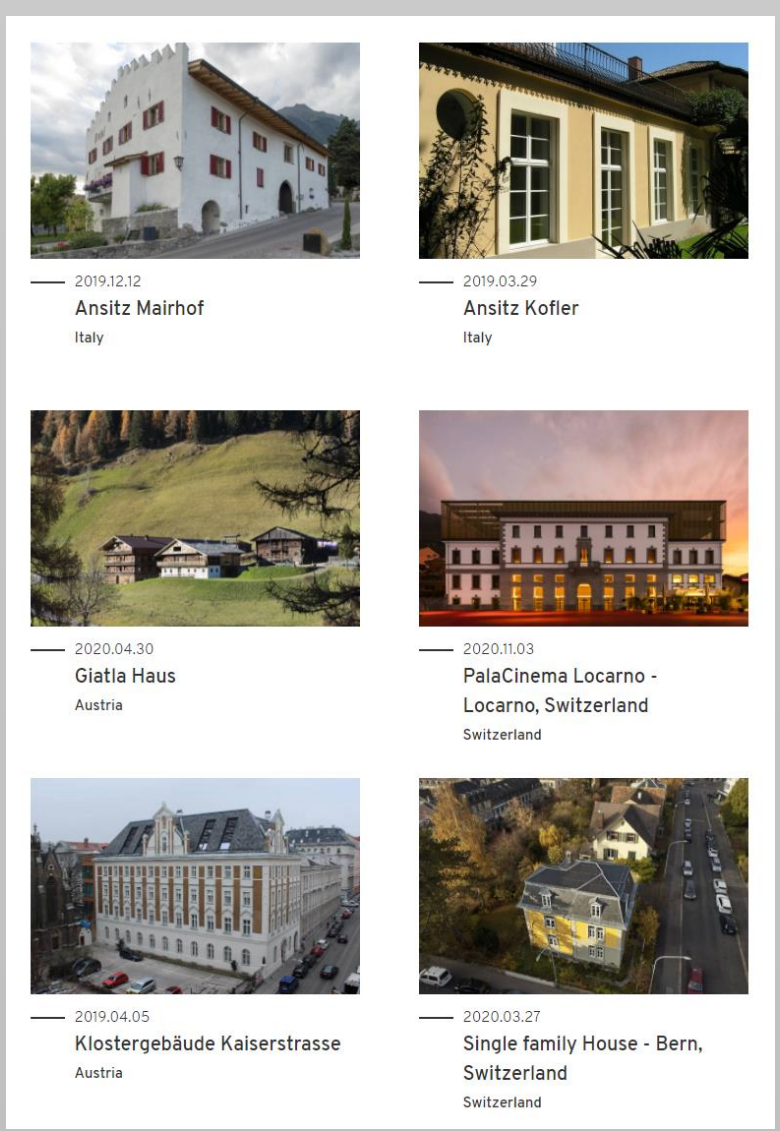

The database contains more than 50 best practice examples of whole building retrofit projects. Browse for inspiration both regarding technical solutions and lessons learned. 
 \\ $\star^{\star^{\star}{ }^{\star}} \quad$ Interreg

HiBERtool, A decision guidance tool for the adoption of energy retrofit solutions in historic buildings.

The HiBERtool contains a catalogue of more than 100 well documented energy efficiency measures. The documentation answers questions like:

- $\quad$-what is the solution? Technical details

- -how can it be applied in practice (examples)

- -why does it work?

- $\quad$ pros and cons

\subsection{Introduction to the case studies}

Every historic building is unique and solutions that work well for one case might not work for the next case. Refubishment projects varies enourmously in terms of complexity and level of difficulty. We believe that following a structured planning process is beneficial in every case, but the resources used for planning have to be balanced in relation to the scale and gravity of the total project. Many users have found it difficult to interpret how the steps in EN 16883:2017 can be carried out in practice. To guide and inspire the reader we will use two fictive case studies to illustrate how the different planning steps can be carried out in practice. In the the yellow box you will follow a larger project, with many professionals and stakeholders involved in a complex refurbishment project. In the blue box you will follow a smaller project, with few stakeholders involved and a more straightforward process.
This case is about the refurbishment of a urban 19th century library that has been closed for the public for many years. It has seen alternative us as storage and as office space, but now there is an ambition to reuse it as a cultural center, with exhibition spaces, studios and a café. The building is officialy listed mainly for its neoclassical exterior, but there are also many preserved interior elements with heritage value. The building has been renovated several times during the 20th century but is currently in a poor overall state. Most of the technical systems (electrical wiring, plumbing, fire security) have to be renewed or updated.

There are many stakeholders involved in this project. The building is owned by the municipality, and the management as well as the refurbishment project is handled by their technical department. The department of culture at the municipality will run the cultural center, and has the role of the client. There are also several other organizations indirectly involved in the planning as they will hire studios and office spaces.

Boel, a civil engineer working at the technical department, is coordinating the project. She is working closely with the director of the cultural department to draft a concept for the refurbishment of the building. The local politicians have asked for a concept and a preliminary budget on which they can decide to fund the project. Boel has been involved in many refurbishment projects before, but she has little experience with historic buildings and is therefore uncertain about how to proceed with the planning.

\section{THE FARMHOUSE - INTRODUCTION}

This case is about the renovation of a half-timbered 18th century farmhouse owned by a young couple. The building was previously owned by an elderly couple and the last major renovation was made in the 1960s. The owners want to refurbish the building to a comfortable home for their family, and at the same time preserve the character of the building. They are concerned about the environment and want their home to have a low carbon footprint. 


\section{HIBERATLAS BEST PRACTICE EXAMPLE [LINK]}

\section{Klostergebäude Kaiserstrasse: Benefits of using a structured, multidisciplinary planning process}

A multi-purpose used convent building in the heart of Vienna was refurbished with particular attention to monument preservation and to a new solution for renovating Viennesetype box windows.

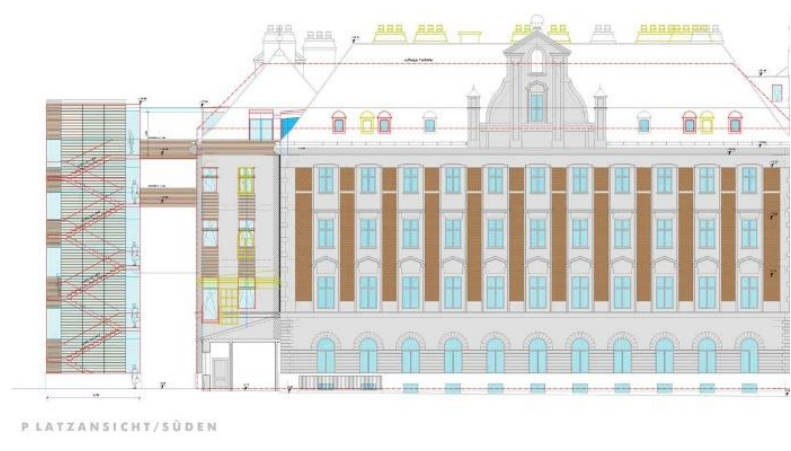

Photo credit: Trimmel Wall Architekten STGmbh

The building and it's court were already under monument protection by the Federal Monuments Authority Austria when the project started. The architectural quality in particular the appearance of the main façades with clinker surfaces, the historic windows \& dormers, the house chapel and the shape of the roof were worth preserving. An innovative package of measures for the preserved Gründerzeit house was conceived as follows: The Viennese box windows in the articulated facades covered with ceramic tiles were preserved and supplemented with passive-house-fit internal wooden windows and energetically optimized. The thermal quality of the building envelope was enhanced by an interior insulation with calcium silicate panels. A comfort cover with a central ventilation unit and heat recovery for the living and recreation rooms was integrated into the historic building fabric. The Gründerzeit roof truss was statically reinforced and thermally renovated while retaining the existing roof contour, the ornamental gable and the historic old slate cover. Light strips were integrated into the space-side roof areas, with the built-in residential units close to the passive house receiving roof terraces on the courtyard side. An external insulation was designed on the inner court facades and fire walls. Through a monitoring of the Vienna University of Technology, the demonstration project was scientifically monitored over a period of 2 years. By applying this innovative package of measures, it was demonstrated how a listed building can be adapted to a highly efficient and upto-date standard of comfort and energy consumption.

The goal was to present a sustainable system solution with the energetic refurbishment of the existing building and the highly efficient loft conversion according to the requirements of the monument protection. This solution should have a high multiplicativity for a large number of Gründerzeit buildings. The property had significant static, fire safety and thermal deficiencies that had be addressed. Futhermore the measures should increase the user comfort by adding an elevator and a small building extension. Both the investment costs of the implemented innovative measures and the running costs in the operation were to be documented in order to be able to perform life cycle cost calculations. The goal was a certification, which documents a holistic representation of the building according to defined sustainability criteria.

The most relevant finding from the Kaiserstraße project is that complex refurbishment projects can only be realized with a consistently ambitious planning team and an openminded client. A continuous process of coordination between an experienced planner and the building preservation authority is necessary. Especially the complication of the strict monument protection for facade and roof landscape shows that an ambitious architect can develop innovative solutions with general applicability from the alleged impediments. One of the keys to costeffectiveness is the expansion of floor space by $30 \%$ and the adaptation of usable space to well-rentable standard, again of particular value the newly created attic floor space. The main contribution of the Kaiserstraße project seems to be that even under the complex conditions of monument protection, high-quality renovations enable innovative, contemporary solutions. 


\section{PART 2 PLANNING THE PROJECT}

\subsection{Establishing the context}

Energy retrofits of historic buildings have to be carefully planned. The first step is to establish the context of the project. In practice, this will be carried out in different ways depending on the complexity and size of the project. This step aims to provide tentative answers to questions such as:

- why was the project initiated and what is the overall aim of the project?

- what is the budget?

- what funding resources are available?

- what is the overall state of the building? Are there obvious problems or limitations?

- who are the stakeholders?

- what qualifications are needed?

- what is the planning status? Is the building officially protected?

To gather the stakeholders and disciplinary experts at this early stage will be beneficial in the end. Especially the involvement of heritage experts at an early stage in the project planning has proven to be tremendously important. If this is not done, there is a risk that the project takes a wrong direction, which will be costly to modify at a later stage in the planning process.

\subsection{Gathering the project team}

It is essential to involve the right competences. Which competences that are needed depends on the scale and complexity of the project, and there might be legal requirements. An energy consultant with historic building experience is in many cases a stated requirement if funding is being sought.

\section{Checklist for the planning of the project}

$\square \quad$ Gauge the budget for the project

$\square$ Define the (tentative) overall aims of the project

$\square$ Identify the legal planning status of the building

$\square \quad$ Contact the heritage/planning authorities and discuss the plans

$\square$ Visit the building and make an initial assessment

$\square$ Identify the competences needed for the planning of the project

$\square \quad$ Identify funding opportunities

$\square \quad$ Involve the client

$\square$ Make a plan for the planning of the project (!)

$\square$ Gather a multidisciplinary team of experts

$\square$ Make a quick visual inspection of the building with the multidisciplinary team

$\square$ Gather stakeholders and experts for a briefing of the project

EN 16883:2017 requires that a multidisciplinary team is involved, but in small projects the "team" might consist of only one member, for example an experienced restoration architect. In larger projects, the challenge is to involve all competences at the right moment in the planning process, in order to avoid parallel work and siloing. The division between different professions, their field of competence and their roles in the planning process vary considerably between different countries. 
Here are examples of professionals that often need to be involved when planning energy retrofits of historic buildings:

- -Architects

- -Restoration architects

- - Craftspersons and conservators

- -Heritage experts

- $\quad$-Building services engineers

- -Energy consultants

- $\quad$-Structural engineers

- -Building surveyors with expertise in building pathology

It is strongly recommended that there are individuals in the project team that have previous experience from working with historic buildings. It is also advisable that heritage expertise is present within the project team and not outsourced.

The planning of the project should also be carried out in cooperation with the owners and users of the building, if possible. Engaged clients can contribute to the project in many different ways, from identifying what is worthy to preserve to customized technical solutions.

\subsection{Assigning responsibilities and lines of communication}

Gathering a competent team is necessary but not sufficient. The project leader should make sure that responsibilities are assigned to the respective team members, and that clear lines of communication are established. A "plan for the planning" is necessary, and this plan should be circulated and acknowledged by everyone involved. The plan should answer questions like: who is responsible and who are involved in each planning step? When will things be done and how should results be documented and presented?

\section{Success factors for planning the project}

$\checkmark$ Heritage experts/authorities should get involved early in the refurbishment process. If not, there is a risk that either heritage values are neglected or that the project is cancelled too late.

$\checkmark$ The energy retrofit should be integrated in a wider context of renovation. There are often established working processes that have to be integrated, rather than paralleled by, the planning of energy efficiency measures

$\checkmark$ Sufficient expertise (e.g. in building pathology, heritage value assessment) is involved from the outset.

$\checkmark$ Ensure that all stakeholders and decision-makers have an open mindset. Do not decide on e.g. specific technical solutions early on.

$\checkmark$ Responsibilities and lines of communication should be determined from early on. Energy efficiency and other aspects that run across disciplinary borders can otherwise be forgotten or handled in parallel by different working groups. 


\section{HIBERATLAS BEST PRACTICE EXAMPLE [LINK]}

\section{Elementary School in \\ Mulhouse, France: succesful dialogue with owner, planning team and heritage authorities}

This hard-stone elementary school is located in Mulhouse in the Alsace region (north-eastern France), near the border with Germany. It is a listed building, as it witnesses the history of the city of Mulhouse : it first was a spinning factory at a time which Mulhouse was well-known for its textile industry and became a school after the annexation of Alsace and Moselle by Germany in 1870. It has recently been retrofitted. The project reaches a balance between low energy consumption and heritage preservation, despite a constraint budget. The school is one of the case studies of the CREBA (French knowledge center for responsible retrofit of heritage building) website.

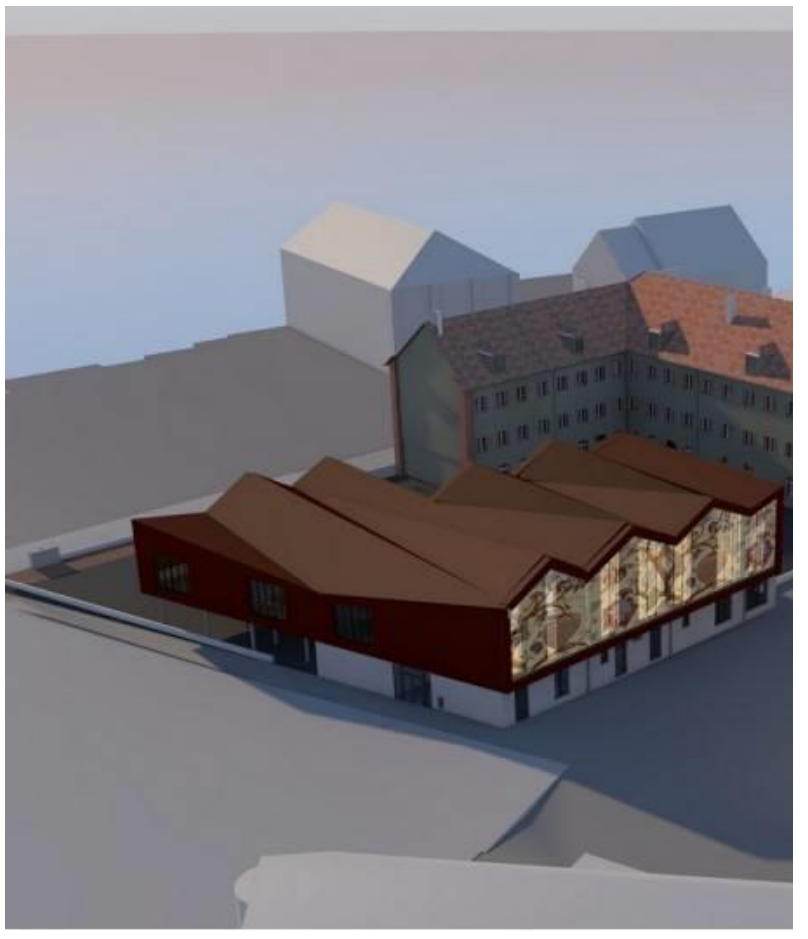

3D-view of the Elementary school in Mulhouse. Credit: Pierre Lynde

The retrofitting project lasted from 2015 to 2017. This project is part of a wider program, aiming to retrofit all the Mulhousian schools and create the best conditions possible for pupils. The project in particular consists in two differents ones : - the retrofitting of the existing building - the construction of a new building in the backyard, sheltering the canteen, sanitations, rooms for after-school activities and a sports hall. Because of the presence of a listed building near the new construction, the validation of the works by the Alsatian architectural review board was required by regulation. For the retrofitting, the project owner had several objectives : - strengthening of the structure ; adressing regulatory obligations, like the risk of fire and the seismic risk, as Mulhouse obtains the rating of 3 on the French seismic risk scale, going from 0 to 5 , but also ensuring accessibility for disabled people ; - improving the indoor air quality, even above the French regulatory standards, but also the acoustic comfort ; - conserving the listed parts of the building but also the rare remaining of the interior design ; - keeping the costs under control, because of a restraint budget ; - and, of course, reducing the energy consumption. In the first version of the project, achieving the French low energy building ("Bâtiment basse consommation") label was not an objective. But thermal simulations showed that it was technically possible. Thanks to a grant from the Alsace Region and the French environment and energy management agency, the label was also financially achievable. The project management team was composed of an architect as the project supervisor and several engineering consultants specialised in building physics, structure, electricity, acoustics and building services. The craftspeople were coming from the near region and were medium-sized companies.

The project management team used building information modeling (BIM) for the construction of the new building but also for the retrofitting of the existing one. This has prevented conflits between technical and architectural decisions. It was also a powerful tool to communicate with every stakeholders, including the project owner. This project was difficult in many ways : first, it was a double project, with both a new construction and a retroffiting ; - then, mercury pollution in the backyard had not been anticipated, resulting in extra costs. - the retrofitting building was in a very bad state, because of structural issues, but also previous works that engendered moisture accumulation. - finally, a real effort of communication has been necessary to find compromises between low energy consumption, heritage preservation and the constrained budget. 


\subsection{Integration with existing work processes and standards}

Does implementing EN 16883:2017 mean that we have to replace our existing work processes and start from scratch? Are we going to implement a new planning process on top of what we (in our organization) usually do? The answer is of course no. Existing processes that work well should be kept, and we should not throw the baby out with the bathwater. Modifications and additions should be done with respect to the special requirements that are needed when working with historic buildings. Projects with historic buildings tend to be more unpredictable, more complex and require more customized solutions than standard projects.

\section{Library - Planning the Project}

To further establish the context of the project, Boel decides to gather a group of people to do a preliminary inspection of the building. Prior to the meeting, she quickly checks the existing documentation of the building, including the documentation made in connection with the designation of the building as a listed heritage. She contacts the local heritage office and informs about the renovation plans. At the heritage office they are happy to be involved in the project already at the conceptual design stage, and sends a building conservation officer to join the inspection. Boel also contacts a building services engineer as well as the current caretaker of the building.

The group gathers and makes a tour of the whole building, from basement to rooftop. The idea is to do a quick assessment of the status of the building, but also that a multidisciplinary discussion about the project as a whole is initiated. After the inspection, the group meets at the office and Boel outlines the preliminary concept for the renovation. The conservation officer informs about what is required in terms of paperwork related to the building permit, and how the construction work has to be supervised and documented in order to fulfil the requirements of the heritage Act.

At this point of the project, there are few answers and many questions. For example, it is not possible for the building conservation officer to say what is allowed and not according to the heritage Act, neither it is possible for the engineer to assess the efficiency of energy retrofit measures. What can be done here, is to make up a plan for how to proceed, and to determine what competences that are needed: gathering the project team. A common vision for the refurbishment of the building is also starting to take shape at this moment.

Boel writes a promemoria where she identifies the overall aims of the project. She points at the need for a thorough building survey, as well as a heritage value assessment. She also recommends that an architectural firm with experience from restoration of historic buildings is contracted for the conceptual design phase.

The aspect of energy efficiency is only one of many aspects in a complex project like this. There are also many established working processes where the concepts from EN 16883:2017 have to be integrated. It is therefore a need for Boel and her collegues to interpret and translate the standard to make it work with their already established procedudes.

\subsection{Working with stocks, districts and communal solutions}

EN 16883:2017 has the individual building in focus, but the decision framework can easily be applied to the planning of energy retrofits in more than one building. In both urban and rural areas there is often a possibility to use communal technical solutions and infrastructure, such as district heating and cooling, shared microgeneration, energy storage, boiler rooms, utility rooms etc. As an example, the surplus heat from the cooling of office spaces can be used in a neighbouring building for domestic heating. 


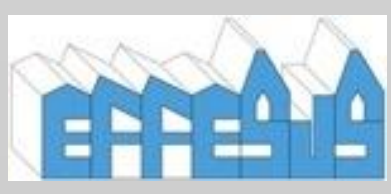

EFFESUS - Energy Efficiency for EU Historic Districts' Sustainability - was a research and development project carried out under the EU Seventh Framework

The overall objective of EFFESUS was to develop and demonstrate, through seven case studies, a methodology and criteria for selecting and prioritising energy efficiency interventions, based on technologies and systems compatible with heritage values, to achieve significant life cycle energy efficiency improvements in the retrofitting of historic districts.

The four main scientific objectives were:

1. Categorisation of European historic districts and development of a multiscale data model

2. Evaluation, development and implementation of cost-effective technologies and systems for significantly improving energy efficiency in historic districts

3. Development of a methodology and a software tool to assess energy retrofitting interventions in historic districts

4. Overcoming technical and nontechnical barriers for the implementation of project results

The main output of the project was be a Decision Support System (DSS), a software tool, which includes all the parameters needed to select appropriate energy efficiency interventions for historic districts.

\section{http://www.effesus.eu}

Heritage significance is also something that can benefit from a zooming out from the individual building. By using the district scale, it is possible to set targets for categories of buildings, as well as identifying risks that accumulate as the sum of many small individual changes to buildings.

\section{FARMHouse -PLANNing the Project}

The owner starts the project by contacting the municipality to find out the planning regulations for their building. They find out that they will need a building consent for any external changes to the building. Together they make an overall budget of the project and write down things they want to achieve with the project. They decide to contact Andrea, an architect with a special interest in traditional buildings, to help them with a concept for the renovation. They discuss their plans with Andrea, who comes for a visit. Together they make a plan for how to proceed with the planning of the project. The farmhouse is in a conservation area, and described as a typical example of a rural farmstead in a municipal building inventory from the 1980s. The owners are unsure about the level of protection and what is allowed to do with the building in relation to heritage legislation. Andrea is comforting, she has some experience from similar problems and explains that as long as the interventions are sound and preserve the external character of the building, there will be no problem to get consent. It is decided that Andrea should do a building survey, incorporating also a basic heritage value assessment based on her experience.

\subsection{Further reading for planning the project}

Troi, A., \& Bastian, Z. (2014). Energy Efficiency Solutions for Historic Buildings.

Herrera-Avellanosa, D., Haas, F., Leijonhufvud, G., Brostrom, T., Buda, A., Pracchi, V., Troi, A. (2019). Deep renovation of historic buildings. International Journal of Building Pathology and Adaptation, 38(4). https://doi.org/10.1108/IJBPA-12-2018$\underline{0102}$

Webb, A. (2017). Energy retrofits in historic and traditional buildings: A review of problems and methods. Renewable and Sustainable Energy Reviews, 77, 748-759. https://doi.org/10.1016/i.rser.2017.01.145

Changeworks. (2008). Energy heritage: a guide to improving energy efficiency in traditional and historic homes. Retrieved from Changeworks Resources for Life website: http://www.changeworks.org.uk/content.ph p?linkid=373 
Mazzarella, L. (2015). Energy retrofit of historic and existing buildings. The legislative and regulatory point of view. Energy and Buildings,

95 ,

23-31. https://doi.org/10.1016/j.enbuild.2014.10.07 $\underline{3}$

Historic England. (2019). Heritage Counts 2019 There's No Place Like Old Homes: Re-Use and Recycle to Reduce Carbon. Retrieved from

https://historicengland.org.uk/research/herit age-counts/2019-carbon-in-builtenvironment/carbon-in-built-historicenvironment/

Pracchi, V. (2014). Historic Buildings and Energy Efficiency. The Historic Environment: Policy \& Practice, 5(2), 210-225. (none).

Rodriguez-Maribona, I., \& Grün, G. (2016). Energy Efficiency in European historic urban districts - a practical guidance. Retrieved from EFFESUS website:

http://www.effesus.eu/wpcontent/uploads/2016/06/EFFESUS Bookl et Final-Version.pdf

Historic England, 2018. Energy Efficiency and Historic Buildings. How to Improve Energy Efficiency.

MIBACT. (2015). Guidelines for the improvement of energy efficiency in cultural heritage. Italian Ministry of Cultural Heritage and Activities and Tourism.

Marincioni, V., Gori, V., de Place Hansen, E. J., Herrera-Avellanosa, D., Mauri, S., Giancola, E., ... Rieser, A. (2021). How Can Scientific Literature Support Decision-Making in the Renovation of Historic Buildings? An Evidence-Based Approach for Improving the Performance of Walls. Sustainability, 13(4),

2266. https://doi.org/10.3390/su13042266

Buda, A., de Place Hansen, E. J., Rieser, A., Giancola, E., Pracchi, V. N., Mauri, S., ... Herrera-Avellanosa, D. (2021). Conservation-Compatible Retrofit Solutions in Historic Buildings: An Integrated Approach. Sustainability, 13(5), 2927. https://doi.org/10.3390/su13052927

Short Guide: Fabric Improvements for Energy Efficiency | HES | History (historicenvironment.scot)

\section{RIBuild}

The RIBuild project provides state-of-the-art knowledge on internal insulation in historic buildings. The website ribuild.eu transforms the latest research into guidelines about visual assessment of your building, possible damages and moisture risks, and tools to collect building specific data and select internal insulation solutions.

On the project website you will find background information about internal insulation as well as an overview over existing systems. There are also guidelines and tools for planning, risk assessment, LCA and LCC related to internal insulation.

Research activities in RIBuild included tests of various internal insulation systems and how they performed in actual buildings under various climate conditions. More than 30 cases were studied and the documentation is available on the website.

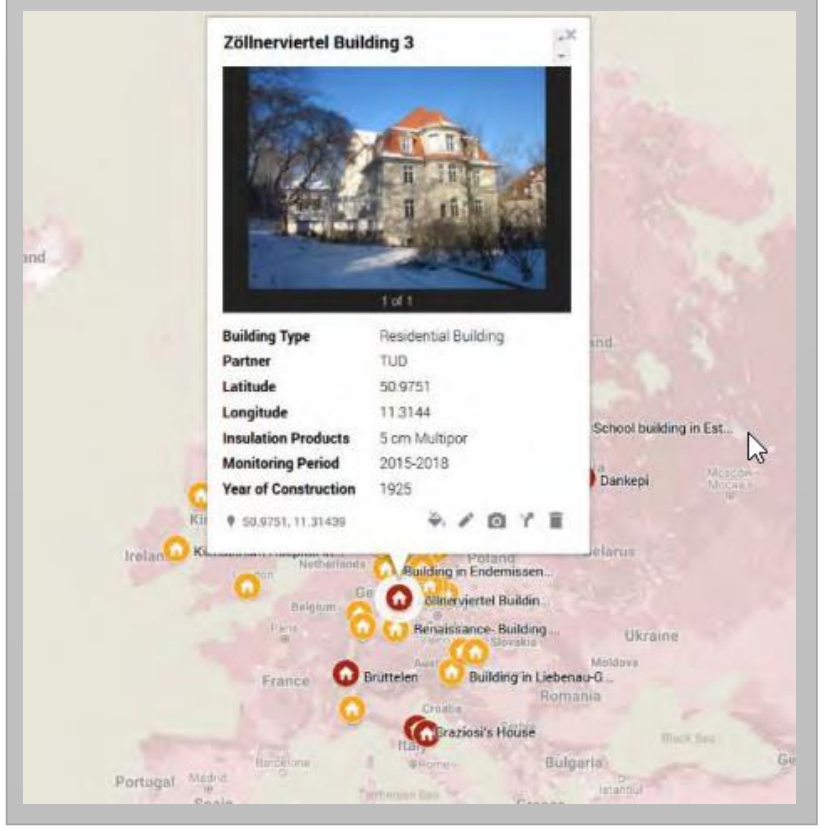




\section{PART 3 BUILDING SURVEY}

A multidisciplinary understanding of the building and its use is the fundament on which all decisions about alterations of historic buildings should be based. All energy retrofit projects of historic buildings should therefore start with a survey and assessment of the building. Without proper information about the current state of the building, its technical characteristics, its use and its heritage significance, it is difficult to assess the consequences of various proposed energy retrofit measures. Furthermore, a thorough understanding of the building is often needed in order to identify innovative energy retrofit solutions.

A common mistake is to have strong ideas about what measures to implement before the building survey is carried out. This can also be a source of bias when the building survey is carried out, e.g. certain aspects can be ruled out as irrelevant. All aspects of the building survey should therefore be considered to some extent. By following the recommendations given in this section you will be sure that vital information is in place before discussing solutions.

It is important that the extent of the building survey is proportionate to the requirements of decision-making, in order to avoid that irrelevant data is gathered to no or little use. To keep in mind is that there are often existing regulations and conventions to follow for the different parts of the survey.

The European standard EN 16096 Condition survey and report of built cultural heritage is a useful generic reference for this part of the planning. EN 16096 emphasizes the need to carefully plan the survey, and to have a structured way of recording and storing data. The overall idea is that the survey results should be useful also after the project is finished. It is therefore a need to systematically describe the data.

The building survey is divided in three major parts:
- Heritage value assessment

- Use of the building

- Technical survey (including Building envelope, Technical systems, Energy performance and Indoor air quality)

\section{FARMHOUSE - BUILDING SURVEY}

The owners consult the local archives to understand more about the history of the building. Based on this material, they can trace how the building has changed appearance during the 20th century through various phases of renovation. Andrea is surveying the building itself and makes detailed digital drawings. She also points at objects and surfaces which she thinks should be preserved. The owners complement her professional assessment based on features that they appreciate with the building.

An energy certificate was issued before the building was sold. It used calculated values to determine an EP of $310 \mathrm{kWh} / \mathrm{m} 2 /$ year for the building (which probably was far more than the elderly couple actually used, as they only heated a small part of the building). Anyways, the data from the energy certificate is considered useful by Andrea and it is decided that no further investigation of EP before intervention is needed.

The information gathered during this phase is documented by Andrea and communicated with the owners. In this case it was possible to carry out the survey rather quickly, but it is important to not be too superficial in this phase. A comprehensive and, where needed, detailed understanding of the building is important for identifying the solutions that are sustainable in the long term.

\subsection{Heritage value assessment}

Assessing the heritage significance of a building is an essential step in all projects. An understanding of what physical features of the building that are carriers of cultural heritage values will make it possible to assess which specific measures that will have a negative effect, and which measures that will have an 
acceptable or positive effect on the heritage significance.

Even if a building is formally protected, there is often a potential to find energy retrofit interventions that are appropriate for the building. For a further discussion about this, see the introduction. It is not uncommon that the formal designation is lacking details about the heritage values and in which ways they are manifest in the physical elements of the building. A heritage value assessment is therefore often needed to complement, update and clarify the official designation.

In addition to a descriptive section where the heritage values are described and motivated, there can be a section where the aspirations according to both stakeholders (owner, client, users) and formal authorities are outlined. Priorities among different alternatives should be detailed if possible, as well as consequences if character-defining elements are lost or altered.

There are many resources available on how to carry out heritage assessments, see below under further reading and resources. Some generic considerations are listed below, but this is a task that should be carried out by a heritage professional, capable of adapting the methodology to the individual case.

The heritage value assessment can be informed by a multitude of sources, which can be differentiated between primary and secondary sources. The assessment is carried out in two separate steps, data acquisition and analysis.

Examples of primary sources:

- original drawings, plans etc

- documentation of previous alterations

- planning documents

- the building itself

- views of users and stakeholders

Examples of secondary sources:

- books, articles etc about the building

- conservation reports

- previous heritage value assessements
Examples of conservation principles and values from Historic England

\section{Conservation principles}

Principle 1: The historic environment is a shared resource

Principle 2: Everyone should be able to participate in sustaining the historic environment

Principle 3: Understanding the significance of places is vital

Principle 4: Significant places should be managed to sustain their values

Principle 5: Decisions about change must be reasonable, transparent and consistent

Principle 6: Documenting and learning from decisions is essential

\section{Values}

- Evidential value: the potential of a place to yield evidence about past human activity.

- Historical value: the ways in which past people, events and aspects of life can be connected through a place to the present it tends to be illustrative or associative.

- Aesthetic value: the ways in which people draw sensory and intellectual stimulation from a place.

- Communal value: the meanings of a place for the people who relate to it, or for whom it figures in their collective experience or memory.

Examples of methods used in the data acquisition:

- - Visual inspection of the building documented with photographs and notetaking.

- - Archival research. Historic sources such as planning documents, drawings, historic maps etc can give important information about the original building and how it has changed through time. 


\section{Checklist for the heritage value assessment}

- Plan the heritage value assessment to be proportionate to the heritage significance of the building

$\square \quad$ Make sure that the one(s) performing the assessment has the relevant qualification

$\square \quad$ Specify the aim for the assessment

$\square$ Build on previous work. Are there existing assessments done?

$\square$ Document the assessment process

$\square \quad$ Make sure that the assessement points out specific elements worthy of preservation, as well as consequences for the heritage significance of the building if such elements are altered or removed.

$\square$ Control if there are archeological remains in the building that have to be excavated before or during renovation work.

$\square$ Use stakeholder participation to elicit community values

- Technical building survey. A number of low- and high tech surveying techniques can be used depending on the complexity and ambitions of the project. These include but are not limited to: geometric measurement, laser scanning, photogrammetry, RTI-imaging. Archaeological methods to determine how building components relate to each other can be used to explain how the building has changed.

- Archaeometry.

Examples of methods from conservation science for gathering information about building components are: dendrochronology, scanning electron microscopy, x-ray fluorescence. Interviews, focus groups, surveys etc can be used to gather data from people about the history of the building, as well as about the social and cultural value of the building.
The aim of the analysis part is primarily about the identification and motivation of the building's heritage values, and how these correspond to character-defining elements of the building.

Suggestions for what the analysis part can include:

- The history and development of the building

- The context of the building, both geographical and social

- Overview of construction techniques and materials

- Uses and functions of the building throughout its history

- Summary of previous alterations and building phases

- Identification of which elements of the building that represent heritage values (and to what extent)

- Risk/vulnerability analysis: which parts of the building are vulnerable to change.

\section{Success factors for the heritage value assessment}

$\checkmark$ The results of heritage value assessments are described in specific terms and in relation to specific features of the building. This makes it possible to assess the impact on heritage values of specific interventions.

$\checkmark$ The heritage expert involved in the assessment is knowledgable about the energy retrofit planning process and has an interdisciplinary understanding of the role of the heritage value assessment.

$\checkmark$ Different stakeholders/stakeholder groups are invited to contribute to the assessment, this is especially important in projects where local communities are involved.

$\checkmark$ Heritage expertise is involved throughout the planning process, and not only as a one-shot, disconnected activity. 


\section{OVERVIEW OF APPROACHES AND METHODS TO HERITAGE VALUE ASSESSMENTS}

\begin{tabular}{|c|c|c|c|}
\hline $\begin{array}{l}\text { Method/ } \\
\text { approach/ } \\
\text { practice }\end{array}$ & Description & Comments & Ref. \\
\hline $\begin{array}{l}\text { The Burra charter } \\
\text { process }\end{array}$ & $\begin{array}{l}\text { The Burra charter process gives the sequence } \\
\text { of investigations, decisions and actions needed } \\
\text { in order to manage heritage assets. } \\
\text { Assessment of heritage values is part of the } \\
\text { first step of the process. The second step of } \\
\text { the process is about developing a maintenance } \\
\text { policy for the heritage asset and finally acting } \\
\text { according to policy is ending this process. }\end{array}$ & $\begin{array}{l}\text { The Burra charter is an } \\
\text { adaption of the Venice } \\
\text { charter aiming at } \\
\text { introducing a more } \\
\text { systematic approach in the } \\
\text { heritage sector. }\end{array}$ & $\begin{array}{l}\text { (Marquis-Kyle and } \\
\text { Walker, 2004) }\end{array}$ \\
\hline $\begin{array}{l}\text { Conservation } \\
\text { principles, policies and } \\
\text { guidance - for the } \\
\text { sustainable } \\
\text { management of the } \\
\text { historic environment }\end{array}$ & $\begin{array}{l}\text { Historic England has developed a guide on } \\
\text { national conservation principles and policies. A } \\
\text { typology consisting of four main values is } \\
\text { proposed; evidential values, historical values, } \\
\text { aesthetic values and communal values. These } \\
\text { values and the significance of the place need } \\
\text { to be assessed through understanding, } \\
\text { identifying and finally articulating the } \\
\text { significance. }\end{array}$ & $\begin{array}{l}\text { The guidance developed } \\
\text { for the specific English } \\
\text { context. However, it } \\
\text { contains general features } \\
\text { that allows the process to } \\
\text { be applied in other } \\
\text { countries. }\end{array}$ & $\begin{array}{l}\text { (Conservation } \\
\text { principles, policies } \\
\text { and guidance - for the } \\
\text { sustainable } \\
\text { management of the } \\
\text { historic environment, } \\
2008)\end{array}$ \\
\hline $\begin{array}{l}\text { DIVE - Urban heritage } \\
\text { analysis }\end{array}$ & $\begin{array}{l}\text { The heritage assessment is incorporated in a } \\
\text { broader process as a component in spatial } \\
\text { planning and development. The assessment } \\
\text { process comprises four steps; Describe (origin, } \\
\text { development and character), Interpret } \\
\text { (elements of importance), Value (tolerance of } \\
\text { change to elements of importance) and finally } \\
\text { Enable (manage and develop). }\end{array}$ & $\begin{array}{l}\text { This procedural method is } \\
\text { developed for planning at a } \\
\text { district level. However, } \\
\text { parts of the process can be } \\
\text { scaled down to the building } \\
\text { level }\end{array}$ & $\begin{array}{l}\text { (Sustainable Historic } \\
\text { Towns: A Handbook } \\
\text { about DIVE - Urban } \\
\text { Heritage Analysis, } \\
\text { 2010) }\end{array}$ \\
\hline $\begin{array}{l}\text { SAVE - Survey of } \\
\text { Architectural Values in } \\
\text { the Environment }\end{array}$ & $\begin{array}{l}\text { SAVE is a Danish method developed as } \\
\text { planning tool. Heritage values are assessed on } \\
\text { a scale from 1-9 using five parameters: } \\
\text { architectural value, cultural-historic value, } \\
\text { environmental value, originality, and technical } \\
\text { value. The five parameters are summed up into } \\
\text { one overall preservation value divided into } \\
\text { three groups: high preservation value (1-3), } \\
\text { Medium preservation value (4-6) and Low } \\
\text { preservation value (7-9) }\end{array}$ & $\begin{array}{l}\text { The method is based on } \\
\text { assessing an overall } \\
\text { heritage value for buildings } \\
\text { rather than pointing at } \\
\text { details or elements in the } \\
\text { building. }\end{array}$ & (Tonnesen, 1997) \\
\hline $\begin{array}{l}\text { Character defining } \\
\text { elements/features }\end{array}$ & $\begin{array}{l}\text { The US Department of National Park Service } \\
\text { provides a guide to identify visual aspects of } \\
\text { historic buildings as an aid to preserving their } \\
\text { character. The guide recommends that the } \\
\text { identification of character defining elements } \\
\text { should be done in three steps. The first step is } \\
\text { to identify the overall visual aspects of the } \\
\text { building, the second step is to identify visual } \\
\text { character at close range and the third step is to } \\
\text { identify interior visual character. }\end{array}$ & $\begin{array}{l}\text { This is a guideline with a } \\
\text { purpose to help owners } \\
\text { and architects to identify } \\
\text { those features or elements } \\
\text { that give the building its } \\
\text { visual character and that } \\
\text { should be taken into } \\
\text { account in order to } \\
\text { preserve them. }\end{array}$ & $\begin{array}{l}\text { ("National Park } \\
\text { Service - US } \\
\text { Department of the } \\
\text { interior, Technical } \\
\text { Preservation } \\
\text { Services," n.d.) }\end{array}$ \\
\hline
\end{tabular}




\begin{tabular}{|c|c|c|c|}
\hline $\begin{array}{l}\text { The P-Renewal project } \\
\text { methodology }\end{array}$ & $\begin{array}{l}\text { The P-Renewal project methodology is a } \\
\text { Belgian process based tool for retrofitting } \\
\text { historic buildings built before } 1914 \text {. The } \\
\text { method is a five step bottom-up approach were } \\
\text { heritage values are identified using the } \\
\text { indicators from the Wallon Heritage } \\
\text { Administration. This approach uses a cross } \\
\text { evaluation matrix with } 11 \text { "interest" criteria } \\
\text { (archaeological, architectural, artistic, } \\
\text { aesthetic, historic, memory, landscape, } \\
\text { scientific, social, technical and urban) and four } \\
\text { quality indicators (authenticity, } \\
\text { wholeness/integrity, scarcity and } \\
\text { representativity). }\end{array}$ & $\begin{array}{l}\text { This is primarily a method } \\
\text { that catgorises the } \\
\text { assessment of cultural } \\
\text { values from a typological } \\
\text { point of view. The } \\
\text { methodological approach } \\
\text { can be transferred to other } \\
\text { national or typological } \\
\text { contexts. }\end{array}$ & (Stiernon et al., 2017) \\
\hline $\begin{array}{l}\text { EFFESUS project } \\
\text { methodology }\end{array}$ & $\begin{array}{l}\text { The EFFESUS heritage value assessment } \\
\text { method is a stepwise process where heritage } \\
\text { values are balanced against an impact } \\
\text { assessment. Heritage significance of a building } \\
\text { or a building component is graded from } \\
\text { outstanding significance (4) to no identified } \\
\text { significance (0) Impact grading of each energy } \\
\text { efficiency measure is set from no impact (0) to } \\
\text { severe impact (4) Balancing of results is done } \\
\text { using a scale from not acceptable to } \\
\text { acceptable. }\end{array}$ & $\begin{array}{l}\text { The method is vague in } \\
\text { describing how statements } \\
\text { on heritage significance } \\
\text { grading are to be made. }\end{array}$ & (Eriksson et al., 2014) \\
\hline $\begin{array}{l}\text { Attribute Significance } \\
\text { assessment }\end{array}$ & $\begin{array}{l}\text { This method is using a three layered analysis } \\
\text { approach in assessing important attributes in } \\
\text { buildings that are about to be renovated. The } \\
\text { analysis contains of a quantitative, a visual and } \\
\text { a qualitative step. The assessment method is } \\
\text { structured around four key elements; scale } \\
\text { levels (area, ensemble, building, building } \\
\text { elements), attributes, heritage significance and } \\
\text { aspects. }\end{array}$ & $\begin{array}{l}\text { This method requires that } \\
\text { the assessment of valuable } \\
\text { attributes in the buildings is } \\
\text { carried out by a group of } \\
\text { experts. }\end{array}$ & $\begin{array}{l}\text { (Havinga et al., } \\
\text { 2019a)(Havinga et al., } \\
\text { 2019b) }\end{array}$ \\
\hline $\begin{array}{l}\text { Framework for a } \\
\text { holistic value-based } \\
\text { approach }\end{array}$ & $\begin{array}{l}\text { This approach is based on a study of existing } \\
\text { heritage value typologies. The approach } \\
\text { consists of three stages of heritage value } \\
\text { assessment. The first stage is to identify the } \\
\text { features of significance of a place, the second } \\
\text { step asks why something is of value and could } \\
\text { be worthy of conservation. The third and last } \\
\text { step is a qualifier of value in order to prioritise } \\
\text { conservation activities. }\end{array}$ & $\begin{array}{l}\text { This approach is presented } \\
\text { in a scientific paper with } \\
\text { the ambition to bridge } \\
\text { theory and practice. }\end{array}$ & $\begin{array}{l}\text { (Fredheim and Khalaf, } \\
\text { 2016) }\end{array}$ \\
\hline $\begin{array}{l}\text { The toolbox approach } \\
\text { and triangulation } \\
\text { method }\end{array}$ & $\begin{array}{l}\text { The complexity of value assessment is the } \\
\text { core of the toolbox approach. Every situation } \\
\text { requires a well-adapted approach to how } \\
\text { heritage values could be assessed. Some } \\
\text { situations has a need for stakeholder } \\
\text { participation, others for expert analysis. The } \\
\text { triangulation method means that assessment } \\
\text { of heritage values is carried out systematically } \\
\text { and with different perspectives a value } \\
\text { statement is made. }\end{array}$ & $\begin{array}{l}\text { This is more an approach } \\
\text { than a method. The } \\
\text { approach assumes that } \\
\text { you have a good } \\
\text { knowledge of the tools that } \\
\text { are relevant to the specific } \\
\text { case. }\end{array}$ & (Mason, 2002) \\
\hline
\end{tabular}


Castaldo, V.L., Pisello, A.L., 2018. Uses of dynamic simulation to predict thermal-energy performance of buildings and districts: a review. Wiley Interdiscip. Rev. Energy Environ. 7, 1-34. https://doi.org/10.1002/wene.269

Conservation principles, policies and guidance - for the sustainable management of the historic environment, 2008. . Historic England.

Crawley, D.B., Hand, J.W., Kummert, M., Griffith, B.T., 2008. Contrasting the capabilities of building energy performance simulation programs. Build. Environ. 43, 661-673. https://doi.org/10.1016/j.buildenv.2006.10.027

Design Builder Software, n.d. Official web site [WWW Document]. URL http://www.designbuilderitalia.it/ (accessed 6.12.19).

EQUA, n.d. IDA ICE - Simulation Software, Official website [WWW Document]. URL https://www.equa.se/en/ida-ice (accessed 6.12.19).

Eriksson, P., Hermann, C., Hrabovszky-Horváth, S., Rodwell, D., 2014. EFFESUS Methodology for Assessing the Impacts of Energy-Related Retrofit Measures on Heritage Significance. Hist. Environ. 5, 132-49. https://doi.org/10.1179/1756750514Z.00000000054

European Committee for Standardization, 2017. EN 16883:2017 Conservation of cultural heritage - Guidelines for improving the energy performance of historic buildings.

European Committee for Standardization, 2011. EN 15898:2011 Conservation of cultural property - Main general terms and definitions.

Fredheim, L.H., Khalaf, M., 2016. The significance of values: heritage value typologies re-examined. Int. J. Herit. Stud. https://doi.org/10.1080/13527258.2016.1171247

Havinga, L., Colenbrander, B., Schellen, H., 2019a. Heritage significance and the identification of attributes to preserve in a sustainable refurbishment. J. Cult. Herit. https://doi.org/10.1016/J.CULHER.2019.08.011

Havinga, L., Colenbrander, B., Schellen, H., 2019b. Heritage attributes of post-war housing in Amsterdam. Front. Archit. Res. 9 , 1-19. https://doi.org/10.1016/j.foar.2019.04.002

Herrera-Avellanosa, D., Haas, F., Leijonhufvud, G., Brostrom, T., Buda, A., Pracchi, V., Webb, A., Hüttler, W., Troi, A., 2019. Deep renovation of historic buildings. Int. J. Build. Pathol. Adapt. 38. https://doi.org/10.1108/IJBPA-12-2018-0102

IES, n.d. Official website [WWW Document]. URL https://www.iesve.com/ (accessed 6.12.19).

Maile, T., Fischer, M., Bazjanac, V., 2007. Building Energy Performance Simulation Tools-a Life-Cycle and Interoperable Perspective.

Marquis-Kyle, P., Walker, M., 2004. The illustrated Burra charter Good practice for Heritage Places, 3rd ed. Australia ICOMOS.

Mason, R., 2002. Assessing values in conservation planning: Methodological issues and choices, Assessing the values of cultural heritage. The Getty Conservation Instittute.

National Park Service - US Department of the interior, Technical Preservation Services [WWW Document], n.d. . Preserv. Briefs 17 Archit. Character - Identifying Vis. Asp. Hist. Build. Aid Preserv. Their Character. URL https://www.nps.gov/tps/howto-preserve/briefs/17-architectural-character.htm (accessed 5.15.20).

Pallin, S., Ph, D., Shrestha, S., Ph, D., Adams, M., 2017. State-of-the-Art for Hygrothermal Simulation Tools.

Schmidt, S., Lindauer, M., Hoppe, M., 2012. Comparing TRNSYS and WUFI ® plus simulation models-illustrated on models validated on measurements at Schack-Gallery Munich, in: Proceedings of the 5th IBPC, Kyoto, Japan, May 28-31.

Schwab, M., 2004. Review of Building Energy Simulation Tools that Include Moisture Storage in Building Materials and HVAC Systems. Dep. Mech. Eng. Univ. Sask. 1-13.

Stiernon, D., Trachte, S., de Bouw, M., Dubois, S., Vanhellemont, Y., 2017. Heritage value combined with energy and sustainable retrofit: representative types of old Walloon dwellings built before 1914. Energy Procedia 122, 643-648. https://doi.org/10.1016/J.EGYPRO.2017.07.363

Sustainable Historic Towns: A Handbook about DIVE - Urban Heritage Analysis, 2010. . Riksantikvaren Norway.

Tonnesen, A., 1997. InterSAVE - International Survey of Architecturel Values in the Environment. Ministry of Environment and Energy The National Forest and Nature Agency, Denmark, Copenhagen.

TRNSYS, n.d. Official website [WWW Document]. URL http://www.trnsys.com/ (accessed 6.12.19).

Webb, A., 2017. Energy retrofits in historic and traditional buildings: A review of problems and methods. Renew. Sustain. Energy Rev. 77, 748-759. https://doi.org/10.1016/j.rser.2017.01.145 


\subsection{Use of the building}

The use of the building is perhaps the most important factor determining its energy use and the potential for preservation of the building itself. Investigate the potential for different uses of the building, as well as if the building offers flexibility in terms om use. To know the historic and existing use of the building is important for understanding the functionality of the building and for upcoming decisions on continued or changed use in the future.

Historic use. The historic use of the building can provide clues about how the building can be reused in sustainable ways. Historic use is mainly investigated through archival sources. The building itself can also give information about the historic use.

Existing use. How is the building used today? Use occupancy schedules to investigate how the building is actually used. Is the existing use in conflict in known or obvious conflict with targets for energy efficiency or heritage preservation?

Future use. Consider the future use early in the planning process. It is essential to find a use for the building that will be sustainable in the long term. See the best practice example below for an example of the dependencies between the building fabric, the technical installations and the use of the building.

Involving users is essential here. Thermal comfort is addressed below under indoor and outdoor climate, section 3.5.
BEST PRACTICE EXAMPLE

\section{Södra Banco, Stockholm: how a thorough survey of both building and use can facilitate adapted technical solutions.}

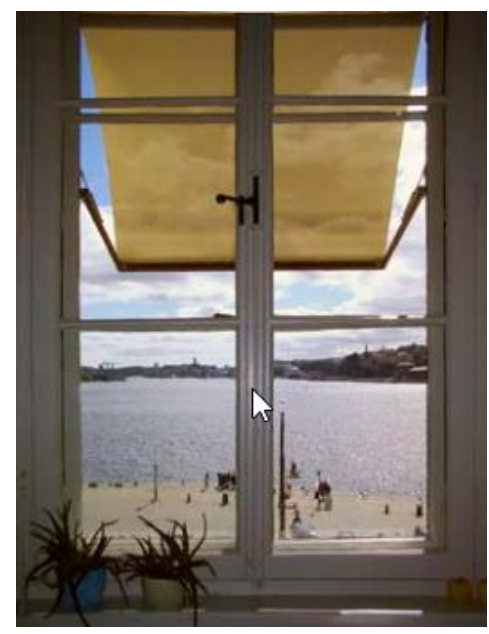

Caption: Window awnings in Södra Banco. Source: https://www.sfv.se/media/asgfhuc0/sfv-ventilation-i-aldrebyggnader-2009.pdf

Södra Banco is a stately owned, listed building that has a continuous use as office building since the late 1600s. The original ventilation system was based on natural draft, with inlet air being infiltration mainly through leaky windows. The system was not performing well and had a number of drawbacks, including overheating in some rooms during summertime. A thorough technical building survey in combination with a review of the use of the individual rooms led to a revision of the ventilation system adapted to the unique circumstances. Minor interventions to the historic fabric made it possible to re-use the existing chimneys for controlled mechanical ventilation and heat exchange. Window awnings, which had historically been used in the building, were installed to mitigate the problems with overheating. Re-used supply air grilles from another building were installed in the stairways. The system works well, but only for its intended use. For example, there is an upper limit of the number of workplaces in each room, and users have to be aware of that closing doors will reduce airflow. If many people gather in the community halls, there is a need to take frequent breaks and manually open windows to let fresh air in. This case study shows how a detailed understanding of the (historic and contemporary) use of a building, its technical installations, and the building fabric facilitate adapted solutions that are energy efficient, provide a good indoor climate and preserves heritage values. 


\subsection{Technical survey}

The technical survey is done to understand the technical status of the building, as well as the opportunities for improving the energy performance. Depending on the nature of the project and the local legislation, there might be legal requirements to include specific documents to get building consent.

\section{Building envelope and technical systems}

There are several aims with the survey of the building envelope and technical systems:

- To plan energy efficiency measures, it is necessary to understand the technical constructions of the different parts of the building.

- The survey also gives input to the energy performance assessment, especially if the latter is calculated from u-values of the building envelope. A thorough survey can also identify cold bridges, draughts etc. See below under energy performance.

- Building defects and moisture problems should be identified to avoid surprises at a later stage in the process

- The heritage value assessment is informed by the survey of the building envelope by discovering e.g. phases of renovation and rebuilding. It is therefore often wise to integrate the heritage value assessment and the technical building survey.

- Existing technical systems can often be used also after retrofit.

- Obsolete technical systems can sometimes be re-used, for example old ventilation ducts.

\section{LIBRARY - TECHNICAL SURVEY}

The original wall construction is a massive brick wall, plastered on out- and inside. During the many renovations there have been additions and modifications and there is some uncertainty about the structure and the materials. A condition survey of each part of the building envelope is carried out, following the standard EN 16096. In some strategic places, samples are drilled in the wall in order to understand its composition.

The existing heating and ventilation system is also surveyed. It is discovered that most of the original ducting is not in use, including many of the chimneys. Parallel ducts have been put up and there is a discussion if these can be removed and the old ducts can be re-used.

In general, there is not much that is added to the technical survey compared to other projects that Boel has been involved in. The survey has to be carried out anyways, but in a historic building like this more care is given to certain aspects. For example, great care is taken to limit the impact on the historic fabric when surveying with destructive techniques (such as drilling samples).

In old buildings that have been renovated and rebuilt throughout the years, there is often uncertainty about how different parts are constructed, and if the construction is homogenous. There might be a need to take a number of samples to determine the status of the building part in question, for example through drilling. Drawings of plans, sections, facades often need to be updated, even if there are original ones.

Condition surveys of the building envelope and the technical systems can, for all parts relevant for the project, include:

- a brief description and location

- construction

- materials and dimensions

- hygrothermal properties

- previous alterations

- condition 
Example of methods to include in the technical building survey

- Geometrical survey

- Photography

- Photogrammetry

- Laser scanning

- Infrared thermography to detect leakages and moisture problems

- Monitoring of moisture in walls

\section{Further reading and resources}

EN 16096 Condition survey and report of built cultural heritage

ISO 13822 Bases for design of structures -Assessment of existing structures

EN 15378-1 for heating systems and domestic hot water systems

EN 16946-1 for automation, controls and technical building management systems.

EN 16798-17 for ventilation and air conditioning systems

\subsection{Energy performance}

An assessment of the energy performance (EP) of the building before intervention is used to determine the impact of different energy retrofit strategies. It is also necessary to have a baseline to compare energy use before and after intervention. In rare cases, such as a building in a poor state that will undergo a major refurbishment, there is little use in assessing the energy performance before retrofit. Still, there is a need to carry out a technical building survey to understand the properties of the existing structure.

There are two principal approaches to assess the EP of a building: by measuring actual energy use or by calculating energy use based on the physical properties of the building and information about the indoor and outdoor climate. EN ISO 52000-1 Energy performance of buildings - Overarching EPB assessment Part 1: General framework and procedure gives guidance of how to determine EP using both approaches. There can be national or regional demands on how to carry out EP assessments, and these should always be considered the minimum level of ambition.

EP is of course affected by the use of the building. The future use, and the level of thermal comfort and ventilation should therefore always be considered when assessing EP.

\section{LIBRARY - ENERgY PERFORMANCE}

The building is heated with natural gas and electricity, and it is therefore easy to measure the consumption by looking at utility bills. In addition to the measured value, U-values are calculated for the constructions in the building envelope and a whole building simulation is carried out in Energy Plus. Uncertainty about several of the input parameters makes the simulation pre intervention uncertain. For example, the infiltration rate is not known. The team is therefore not surprised that there is a large discrepancy between the measured $(240 \mathrm{kWh} / \mathrm{m} 2 /$ year $)$ and the simulated (290 kWh/m2/year) energy use. The building simulation is despite this expected to later on provide accurate results when assessing energy savings from different measures.

Actual energy use is often possible to measure through data on the use of gas, electricity, district heating etc (measured consumption). In buildings that are heated with energy sources stored in the building, such as firewood, wood pellets or oil, it is more difficult to measure actual use. The measured energy use should be corrected for differing weather conditions (the energy demand varies in between years). Energy use for domestic hot water should be calculated separately. The benefit of using measured values is that they are based on the actual energy use of the building. In the context of planning for energy retrofits there are several limitations with using measured data. The use of the building might change after retrofit and then there it is impossible to compare energy use. More importantly, measured values gives no information about the EP of individual components of the building. Such information on component level is often necessary to assess the impact of different energy efficiency measures. 


\section{Basic or complex models?}

The EP assessment can vary from a basic model, for example a spreadsheet with the energy balance of the building, to a complex dynamic assessment.

The output of the model will always be dependent on the quality of the input data. A sophisticated model cannot do magic with poor input data. It is therefore a need to match the resources spent on data gathering and the level of sophistication of the model.

Assessing EP by calculation is based on detailed knowledge about the technical properties of the building, its use and the outdoor climate. Examples of input that is needed is $\mathrm{U}$-values of components or building materials, infiltration and ventilation rates, boiler efficiency etc. Which level of detail, as well as which level of confidence in the output, that is necessary depends on the nature of the project. To bear in mind is that historic buildings often have properties that deviate from standard input data, and that detailed on-site investigations might be needed to achieve confidence in the results.

\section{Further reading}

NBN EN 13187 Thermal performance of buildings Qualitative detection of thermal irregularities in building envelopes - Infrared method (ISO 6781:1983 modified)

EN ISO 9972:2015 Thermal performance of buildings. Determination of air permeability of buildings. Fan pressurization method.

Troi A., Bastian Z., 2015. Energy Efficiency solutions for historic buildings: a handbook, Birkhäuser, Basel.

See also below under Simulation

\subsection{Indoor and outdoor climate}

Maintaining a certain indoor climate is an essential function of most buildings, closely linked to their function and use. Simple user surveys can be used to evaluate the existing indoor environment. If the present indoor climate is unsatisfactory due to low temperatures or drafts, the benefit from future energy efficiency measures is likely to be used to increase comfort rather than lowering energy demand.

Depending on the nature of the project, it might be necessary to document the current indoor climate. Ideally, temperature and relative humidity should be monitored over a whole year. However, any data is better than none.

In some historic buildings, housing valuable collections and interiors, the indoor climate is governed not only by human comfort but also by preservation requirements. In such a case a conservation expert should be consulted to specify targets for the indoor climate and the need for monitoring.

Documenting the outdoor climate, either through weather stations or from on-site measurements, will be necessary to provide input to building simulation, see below. It is also necessary for interpreting the indoor climate measurements.

\section{Further reading and resources}

Broström, T., \& Klenz Larsen, P. (2015). Climate Control in Historic Buildings (S. Carlsten, Ed.). Retrieved from http://eprints.sparaochbevara.se/862/

Camuffo, D. (2014). Microclimate for cultural heritage: Conservation and restoration of indoor and outdoor monuments (Second edition.). Waltham: Elsevier.

EN 15758 Conservation of Cultural Property Procedures and instruments for measuring temperatures of the air and the surfaces of objects.

EN 16242 Conservation of Cultural Property Procedures and instruments for measuring humidity in theair and moisture exchange between air and cultural property.

EN 15757 Conservation of Cultural Property Specifications for temperature and relative humidity to limit climate-induced mechanical damage in organic hygroscopic materials 
EN 16893:2018 Conservation of cultural heritage specifications for location, construction and modification of buildings or rooms intended for the storage or use of heritage collections

EN 15232-1 Energy Performance of Buildings - Part 1: Impact of Building Automation, Controls and Building Management

EN 15251 Indoor environmental input parameters for design and assessment of energy performance of buildings- addressing indoor air quality, thermal environment, lighting and acoustics

ISO 17772-1 Energy performance of buildings Indoor environmental quality - Part 1: Indoor environmental input parameters for the design and assessment of energy performance of buildings

EN ISO 7730 Ergonomics of the thermal environment - Analytical determination and interpretation of thermal comfort using calculation of the PMV and PPD indices and local thermal comfort criteria

ASHRAE 62-2001 Ventilation for Acceptable Indoor Air Quality

2015 ASHRAE Handbook HVAC Applications Chapter 23. Museums, Galleries, Archives, and Libraries

\subsection{Building simulation}

The table below provides information about building simulation tools to assess energy- and hygrothermal performance. Each tool is described briefly. For more detailed information, the reader is referred to the references. These tools can be used to simulate the performance of the building pre intervention, but also to assess individual measures. For an overview of critical factors related to historic buildings, and suggestions for how to deal with them, see the following paper:

Akkurt, G. G., Aste, N., Borderon, J., Buda, A., Calzolari, M., Chung, D., ... Turhan, C. (2020). Dynamic thermal and hygrometric simulation of historical buildings: Critical factors and possible solutions. Renewable and Sustainable Energy Reviews, 118, 109509.

https://doi.org/10.1016/j.rser.2019.109509 


\section{OVERVIEW OVER BUILDING SIMULATION SOFTWARE}

\begin{tabular}{ll}
\hline BES tool & Applications \\
\hline Energy- & EnergyPlus is a widespread and accepted tool \\
Plus & in the building energy analysis community \\
& around the world. This programme models \\
& heating, cooling, lighting, ventilation and other \\
& energy flows as well as moisture in buildings. \\
& EnergyPlus performs sub-hourly calculations \\
& and integrates the dynamic performance of \\
& technical systems into the whole building \\
& energy balance calculations.
\end{tabular}

Main limitations
The main limitation of EnergyPlus is the
lack of a graphical user interface. A
complete, simple but flexible user
interface is needed to allow faster and
more convenient user input. The
simulation of thermal bridges and the
integration with CFD software are not
allowed.

Ref.

(Crawley et al., 2008)

Design DesignBuilder is the most comprehensive

Builder interface for EnergyPlus. Its current version includes a simplified CAD interface, templates and compact air system configurations for EnergyPlus. An important feature of DesignBuilder is the help window that provides tips and wizards guiding the user through the creation of the thermal model.

Trnsys TRNSYS is a transient system simulation
software with a modular structure that allows to
simulate a variety of energy systems with
various levels of complexity. It was designed
and tailored to simulate complex energy
systems by decomposing the problem in
simpler and smaller components (called
"types"). Models are constructed in such a way
that users can modify existing components or
write their own, extending the capabilities of
the environment.

\begin{tabular}{ll}
\hline WUFI & WUFI plus is a software tool that connects \\
Plus & dynamic energy simulation and hygrothermal \\
& calculation. It is the most used tool for \\
& evaluating moisture conditions in building \\
& envelopes. WUFI Plus performs 3-dimensional \\
& hygrothermal calculations on building \\
component cross-sections, taking into account \\
built-in moisture, driving rain, solar radiation, \\
long-wave radiation, capillary transport, and \\
summer condensation.
\end{tabular}

IES VE IES VE provides an environment for the geometric representation which is evaluated with ApacheSim engine, a CIBSE qualified model tested using the ASHRAE 140. The dynamic tool ApacheSim can be dynamically linked to the Macro FLO dynamic tool for natural ventilation and HVAC Apache dynamic

\begin{abstract}
A range of common HVAC systems is available in the Design Builder user interface, but do not include detailed information about the components and their topology. The inability to import EnergyPlus input files limits the utility of the program.
\end{abstract}
(Design Builder Software, n.d.; Maile et al., 2007)

$\begin{array}{ll}\text { The major limitation of TRNSYS is to } & \text { (Castaldo and } \\ \text { not being able to connect with AutoCad } & \text { Pisello, 2018; } \\ \text { Software tool for importation and } & \text { Crawley et al., 2008; } \\ \text { exportation of files. } & \text { TRNSYS, n.d.) }\end{array}$

Finally, no type related to specific features of historical building exists.
The radiation model in WUFI plus contains only the so called "geosurf factor method" which distributes the incoming radiation on every surface according to factors not editable by the users.

(Pallin et al., 2017;

Schmidt et al., 2012)

$\begin{array}{ll}\text { IES VE is a commercial program, so its } & \text { (Castaldo and } \\ \text { code is not accessible and the user } & \text { Pisello, 2018; IES, } \\ \text { cannot add any additional simulation } & \text { n.d.; Pallin et al., } \\ \text { modules to enhance either application- } & \text { 2017; Schmidt et al., } \\ \text { oriented or general-purpose modelling } & \text { 2012) } \\ \begin{array}{ll}\text { capabilities. Analysis of thermal bridges } \\ \text { is not considered. }\end{array}\end{array}$


tool to study air leaks and natural lighting. It is

possible to include LCA and LCC parameters.

IDA ICE Physical systems from several domains are in IDA described using symbolic equations, stated in either or both of the simulation languages Neutral Model Format (NMF) or Modelica. IDA ICE offers separated but Although the program is flexible and (Castaldo and easy to use, it can have a long run time, Pisello, 2018; depending on the complexity of the Crawley et al., 2008; model structure. integrated user interfaces to different user categories: simplified, standard or advanced for developers.

[1] Crawley DB, Hand JW, Kummert M, Griffith BT. Contrasting the capabilities of building energy performance simulation programs. Build Environ 2008;43:661-73. doi:10.1016/j.buildenv.2006.10.027.

[2] Maile T, Fischer M, Bazjanac V. Building Energy Performance Simulation Tools-a Life-Cycle and Interoperable Perspective. 2007.

[3] Design Builder Software. Official web site n.d. http://www.designbuilderitalia.it/ (accessed June 12, 2019).

[4] TRNSYS. Official website n.d. http://www.trnsys.com/ (accessed June 12, 2019).

[5] Castaldo VL, Pisello AL. Uses of dynamic simulation to predict thermal-energy performance of buildings and districts: a review. Wiley Interdiscip Rev Energy Environ 2018;7:1-34. doi:10.1002/wene.269.

[6] Pallin S, Ph D, Shrestha S, Ph D, Adams M. State-of-the-Art for Hygrothermal Simulation Tools 2017.

[7] Schmidt S, Lindauer M, Hoppe M. Comparing TRNSYS and WUFI $®$ plus simulation models-illustrated on models validated on measurements at Schack-Gallery Munich. Proc. 5th IBPC, Kyoto, Japan, May 28-31, 2012.

[8] IES. Official website n.d. https://www.iesve.com/ (accessed June 12, 2019).

[9] EQUA. IDA ICE - Simulation Software, Official website n.d. https://www.equa.se/en/ida-ice (accessed June 12, 2019).

[10] Schwab M. Review of Building Energy Simulation Tools that Include Moisture Storage in Building Materials and HVAC Systems. Dep Mech Eng Univ Saskatchewan 2004:1-13.

[11] Wit MH de. HAMBase: Heat, Air and Moisture Model for Building and Systems Evaluation, Bouwstenen 100. vol. 100. 2006. 


\section{PART 4 SETTING THE OBJECTIVES AND THE ASSESSMENT CRITERIA}

Many objectives have to be balanced in an energy retrofit project. Specifying and prioritizing among sometimes conflicting objectives in an early stage of the decisionmaking process is essential. Only when knowing what the objectives are, it is possible to assess various measures.

\section{Success factors for setting the objectives}

$\checkmark$ The objectives are communicated within the project group and with stakeholders.

$\checkmark \quad$ The step is carried out in the beginning of the project and the results communicated within the planning group and with stakeholders. Otherwise it might be that that conflicting objectives are brought to the discussion table when it is too late to change direction.

$\checkmark$ Do not make this step overly complicated or time-consuming. The most important thing here is a mutual understanding for the project partners what is important in the project.

Without knowing what you want to achieve, it is impossible to choose between different alternatives. This is therefore an essential step, although in many practical situations it is not carried out in a systematic and explicit way. People may have different reasons for the energy retrofit of their building. For some, the aim will be to save money on fuel bills. Others might want to focus on reducing greenhouse gas emissions or make a building more comfortable. Furthermore, individuals and organisations involved in the different stages of a project may have varied, sometimes conflicting, priorities and objectives. Understanding the requirements, aspirations and aims of the various stakeholders is key to devising a suitable energy-efficiency strategy.

This step will set out both short and long term objectives for the project. These will later on be used to identify the measures that appropriate and practical in the specific context. To be useful in practice, objectives should be operationalised as a list of critera. Quantitative targets are preferable, but many aspects are difficult to quantify.

The three key objectives to balance in the energy retrofit of historic buildings are preservation, energy performance, and use. In addition to these, there are several more objevtives that have to be met, such as the technical compatibility and environmental impact. The available resources, especially the financial ones, are finally determining of what is possible to achieve and set the boundaries of the project.

Finding measures that fulfil all the objectives set in this part can be impossible. It is therefore important to understand that the setting of objectives is a part of an iterative process. If no appropriate solutions are found, then there is a need to take a step back to revise the objectives. The minimum level of ambition is the legal requirements, which always should be respected.

\subsection{Setting objectives in practice}

In a smaller project, setting the objectives would require as little as a short discussion where the involved stakeholders are present. Starting from any legal requirements, the stakeholders can discuss what they want to achieve with the project and document it. Setting the categories for assessment will also be rather straightforward, starting from a comprehensive list of criteria and excluding those that are not considered relevant of feasible.

In a larger project, a workshop can be arranged where major stakeholders can discuss the areas where targets should be set. In such a workshop it is a good idea to also invite specialists (heritage authorities, conservators, 
engineers) etc that are or will be involved in the project. In practice, there will be existing procedures in place for how to handle many of the aspects covered here.

\section{LibraRy - SETting the OBJECTIVES}

In this large project there are many objectives to be fulfilled. Most of them are already covered by existing procedures and there is little uncertainty about what targets and what criteria to use.

There is however some uncertainty about what level of ambition to use when it comes to both energy perforamce and preservation. Boel and her team at the municipality are used to working with the minimum performance standards set in the national building codes. They are therefore a bit puzzled over how they can set a target for the energy performance of the library building. After studying some data about targets for new buildings, a few recently refurbished similar buildings as well as the EP pre retrofit, they gather for a meeting with the whole planning group and some of the stakeholders.

Based on the information about the building and project gatherered so far, the group has an intense discussion about the level of ambition for preservation and energy performance. It is decided that preservation should be given the overall priority in this building, and that all "elements worthy of preservation" pointed out in the heritage value assessments should be preserved and kept visible. It is decided that technical installations should be hidden as much as possible, and that minor impacts on the historic fabric can be accepted in many cases. Most surfaces are already modified, damaged and renovated.

A realistic energy performance target is estimated based on previous experience in the planning group to be $120 \mathrm{kWh} / \mathrm{sqm} / \mathrm{year}$ of primary energy, which is a little better than in the newly retrofitted buildings that were used to compare with, but far from new standards.

Boel summarizes the meeting, pointing out that these are not the final targets. It will be a challenge to reach $120 \mathrm{kWh} \&$ sqm/year given the many limititations, and the targets might be revised later on in the process. However, the group has now calibrated their objectives and there is a better agreement about in which direction the project should be heading.

What often is missing is that these are discussed and communicated across both disciplinary boundaries and organizational silos. Assessment categories can be selected by experts in the various fields and finally decided in a interdisciplinary meeting. In large projects, there will often be predetermined assessment criteria for various objectives.

\subsection{Heritage significance of the building and its settings}

The building survey provides the necessary input for setting the objectives for preservation. The heritage values of the building are central here - all interventions should be put in relation to how the heritage values are affected. This is not an easy task to carry out in practice: heritage values are quite abstract, while retrofit interventions are very concrete. The fact that it is difficult is not an excuse for skipping it: setting the objectives for preservation is essential for finding the appropriate measures. The keys to success here is to be clear and concrete, and to communicate the objectives with the whole planning group to achieve a shared understanding.

Character-defining elements should be defined in the heritage value assessment. When setting the objectives there is a need to prioritize: which elements must be preserved no matter the cost, which ones are acceptable to change, and which ones are somewhere in between? There can also be interventions that are positive from a preservation point of view, especially related to aesthetic aspects and improved use. Here it is important for everyone involved to understand that the building is more than the sum of its individual parts, and also that its value is related to its urban or rural context.

Setting the objectives for preservation is not only about prioritizing among character-defining elements, it is also about deciding about a general conservation philosophy. Should, for example, technical installations be hidden (resulting in irreversible damage to the building fabric), or carefully added with as little damage to the building fabric as possible (resulting in a less favourable aesthetics)? To what extent should additions be reversible? 


\section{Assessment criteria}

The risks related to heritage significance can be divided into two main categories: material and visual impact. The first category refers to loss or alteration of the historic fabric, such as when a wall is insulated on the inside in a non-reversible way, or when existing window panes are replaced with low energy panes. Here should also potential secondary risks related to technical risks be considered, for example that an existing external plaster might become colder and more prone to damage when the wall is internally insulated. Visual impacts refer to aesthetic and architectural values. For example, when a wall is covered with internal insulation there will be a visual impact which will have a negative impact on the heritage values.

Often, there will be a mix of both types of impact from a single measure. As in the above example where an internal insulation will have both material and visual impacts.

The visual impacts should always be considered in the wider spatial context (urban or rural). The building is not only experienced as an individual artefact, but as a part of a district or a landscape. As such, it is part of a milieu which as a whole can be negatively (or positively) affected by changes to individual buildings.

The heritage value assessment, as described in section $\mathrm{x}$, is the basis for the assessment. Preferably, there should be a heritage expert involved in the assessment of measures. This is however not realistic in smaller projects. A dialogue with the heritage authorities is always recommended and can save a lot of time in the end.

Recommended minimum level of assessment:

- Impact on heritage values: material/visual/spatial

- All measures have to be in accordance with heritage law
THE FARMHOUSE - SETTING THE

\section{Objectives}

Much of the work related to the setting of objectives has already been carried out in the minds of the owners and with the discussions with Andrea. Still, to be able to assess the pros and cons of different measures, the owners decides to write down a few explicit objectives to communicate with Andrea. Firstly, they have ambitions about the functions, and the overall appearance of the refurbished building. Secondly, they have an upper limit when it comes to costs. Thirdly, they want to reach an energy performance that is equivalent to new buildings. Fourth, they want to use environmentally friendly materials, preferably local ones if possible. Lastly, they want the refurbishment to be in accordance with the heritage legislation.

\subsection{Energy performance}

Given that there often are no strict legal requirements on energy performance when refurbishing historic buildings, it is often a delicate issue to achieve consensus regarding this objective.

A strategy to solve this dilemma is to try to achieve "best practice" when it comes to energy performance. But what is best practice when every project and building represent individual challenges? A recommendation is to use other projects and benchmarks as inspiration, but to always try to find the level of intervention based on the potential of the building itself. See the discussion about the "negotiation space" in the introduction.

\section{Assessment criteria}

Energy performance in buildings is defined in national legislation and norms. It is usually expressed as $\mathrm{kWh} / \mathrm{m} 2 / y e a r$ of the heated area of the building. But this metric can be different depending on what is included - the system boundaries. Is it energy need (space heating, cooling and hot water), energy used incloding system losses, delivered energy or primary energy? It is extremely important that there is consistency in calculations, especially when you compare buildings - otherwise you will compare apples with pears. 
Energy performance is already integrated in sustainability assessment schemes in larger projects and where professional owners are involved. Redundant work should of course be avoided.

Recommended minimum level of assessment:

- Calculation or qualified estimate of energy savings

- Fulfilling legal requirements of EP

\subsection{Aspects of use}

Finding an appropriate use of the building is often a crucial part of the longevity of a building. Use, and the behaviour of individual users, are determining for the energy use of the building. It is therefore essential to take into account future use(s) of the building when planning energy retrofits.

The historic and existing use should be considered when setting the objectives for the future use of the building. It should be discussed early on if the new use is in line with the heritage significance of the building. Can new functions be integrated in additions to the historic structure?

There are various ways in which the future use of the building can be specified. One way is to use ccupancy schedules with estimated number of expected users.

Important aspects of the use of a building are regulated in building codes (Indoor air quality, thermal comfort, accessibility, fire safety etc). It is important that the minimum legal requirements are possible to fulfill.

\section{Assessment criteria}

For this objective it is often difficult to use quantitative assessment criteria. A qualitative assessment if the impact of energy efficiency measures is in line with the intended use of the building is often sufficient. See also below about indoor environmental quality.
Recommended minimum level of assessment:

- estimate consequences of a change of use

- estimate the impact on use/users

- estimate the ability of building users to manage and operate control systems

\subsection{Indoor environmental quality}

Thermal comfort requirements are not absolute, they are strongly correlated to the use of the building. This is also often a matter of negotiation and using the opportunities given by the individual historic building in innovative and smart ways. Simply put: If the users are shown an economic benefit of reducing indoor temperature, they are more willing to accept it.

Many large historic buildings can be divided the building into different thermal zones where comfort heating is applied only where needed. Some historic buildings are intermittently used, often depending on the season. Significant savings can be achieved by adapting the heating (or cooling) schedule to the use of the building. Lowering indoor temperature temporarily always gives a net energy savings even if it takes some time and energy to raise the temperature again (given that the power cost is constant, i.e. not applicable to heat pumps). Intermittent requires higher heating power than permanent heating which should be considered in the economic assessment of measures.

When the building is not in use, there is still a need to control the indoor climate in order to prevent moisture problems. Dehumidification and conservation heating, i.e. controlling the indoor climate with respect to relative humidity, are energy efficient alternatives to traditional background heating.

Vulnerable parts of the building fabric as well as movable objects within the building might require a certain indoor climate to reduce the risk of deterioration. Sometimes, such requirements come in conflict with the demand 
for thermal comfort and low energy use. This topic is also covered in section 3.5.

\section{Assessment criteria}

For thermal comfort there are established standards, for example • ISO 17772-1 Energy performance of buildings - Indoor environmental quality - Part 1: Indoor environmental input parameters for the design and assessment of energy performance of buildings

For preventive conservation, see EN 16893:2018 Conservation of cultural heritage specifications for location, construction and modification of buildings or rooms intended for the storage or use of heritage collections

Recommended minimum level of assessment:

- Make sure that legal requirements on IEQ are fulfilled

- Avoid measures that risk moisture problems indoors (i.e. mould growth)

\subsection{Technical compatibility with the existing structural, constructional, technical systems}

Energy efficiency measures will have a direct or indirect physical impact on the building. Even a seemingly harmless measure such as lowering the indoor temperature will lead to a changed hygrothermal state of a building component, and might imply an increased risk of damage.

Mixing materials with different properties can lead to structural issues, a well known example is the addition of a rigid cement mortar leading to structural damage to historic masonry.

In most projects the objective will be to eliminate the risks related to the technical compatibility. There will be exceptions, for example in a building with salt problems and rising damp it might be possible to reduce, but not eliminate, the risk of decay due to salt efflorescence. In any case, it will be difficult to use quantitative targets for the technical compatibility.

\section{Assessment criteria}

The hygrothermal risks can be assessed with both simple and sophisticated methods. Using rules of thumb and previous experience will be sufficient in some cases, in others there is a need to use more sophisticated assessment methods such as hygrothermal simulation of the building envelope.

Hygrothermal risk to the building envelope:

- Biological risks (mould, rot, insects)

- Corrosion risks

- Mechanical risk (shrinking and swelling)

- Salt damage

Structural issues:

- Fittings

- Overload

- impact on the historic fabric

Recommended minimum level of assessment:

- Qualitative risk assessment of technical risks based on previous experience

- Consider the reversibility of assessments

- Fulfil legal requirements

\subsection{Impact on the outdoor environment}

All energy efficiency measures will have an impact on the outdoor environment in terms of emissions of greenhouse gases or other harmful substances, as well as the use of natural resources. Environmental impact assessments have become common in larger construction works, but in smaller projects there is often little attention paid to this important aspect.

The assessment of environmental impacts of an energy efficiency measure are in most practical cases performed in parallel with technical and economic assessments. In general, these assessments have a common purpose: information about the measure should be assessed in order to provide the decision maker, and other stakeholders, with comprehensive and reliable information about 
its performance. According to the EN 156866:2004, environmental impacts associated with constructed assets can be significant and should be addressed in project planning.

Life Cycle Assessment (LCA) is a quantitative method for assessing the environmental impacts of a building throughout its complete life-cycle. In this context, LCA is used to predict and compare the consequences of different proposed measures for a building, and is often focused on grennhouse gases. According to the EN 15643 framework, greenhouse gas emissions on a single solution can be evaluated into three stages: the construction stage (including processes such as the procurement of raw materials, building material production, transportation, and construction), the operational stage, and the demolition stage (including processes such as building demolition and waste material recycling and processing). The maintenance stage can be excluded because various case studies have demonstrated that the sum of the energy needed for the maintenance stage is either negligible or approximately $1 \%$ of the total life cycle energy requirements (Sartori and Hestnes, 2007, Wang, 2009). The saving of CO2eq / year of a building can be evaluated considering the delta in the operational stage due to a reduction of emissions generated by technical installations (heating, ventilation, air conditioning, lighting; others).

There are some common pitfalls in using LCA:

- Using simple assessment tools as a black box, without understanding how they really work, may be tempting. The general rule is that you need a qualified person to do the analysis.

- No life cycle analysis is better than its input data. The available of relevant data on specific environmental impact and specific costs on a component level will always be a limiting factor.

- In LCA/LCC the life cycle is often limited to 30-50 years. This may be problematic in relation to historic buildings.

\section{Assessment criteria}

- LCA of greenhouse gases

- Other harmful substances and emissions

- Natural resource use

Recommended minimum level of assessment:

- Consideration of greenhouse gas emissions from a life cycle perspective

- Consider waste and pollutants

- Fulfil legal requirements 


\section{OVERVIEW OVER LCA AND LCC GUIDELINES AND TOOLS}

\begin{tabular}{|c|c|c|c|}
\hline Name & Short description & Comment & Ref \\
\hline EN 15978:2011 & $\begin{array}{l}\text { European standard: } \\
\text { EN 15978:2011 Sustainability of construction works - } \\
\text { Assessment of environmental performance of buildings - } \\
\text { Calculation method }\end{array}$ & $\begin{array}{l}\text { This standard describes a } \\
\text { calculation method to assess } \\
\text { the life cycle environmental } \\
\text { performance of a building. It } \\
\text { can be applied to new } \\
\text { buildings as well as renovation } \\
\text { projects. }\end{array}$ & 1 \\
\hline oneClickLCA & $\begin{array}{l}\text { One-click-LCA is an easy-to-use software for the compilation } \\
\text { of information and analysis of results facilitating the integration } \\
\text { of sustainability aspects in the decision making process. }\end{array}$ & $\begin{array}{l}\text { Requires a licence } \\
\text { Includes LCC } \\
\text { Easy to use }\end{array}$ & 2 \\
\hline Ascot & $\begin{array}{l}\text { ASCOT - Assessment tool for additional construction cost in } \\
\text { sustainable building renovation. Over the lifespan of the } \\
\text { building, it takes into consideration: } \\
\text { 1) all investment and operation costs } \\
\text { 2) the savings from the investments with respect to } \\
\text { sustainable issues } \\
\text { 3) the reduced environmental impact from the energy savings. }\end{array}$ & $\begin{array}{l}\text { Free } \\
\text { Easy to use } \\
\text { Includes an optimization } \\
\text { It is available in English, } \\
\text { French, Spanish and Italian }\end{array}$ & 3 \\
\hline Gabi & $\begin{array}{l}\text { GaBi models every element of a product or system from a life } \\
\text { cycle perspective It provides an easily accessible and } \\
\text { constantly refreshed content database that details the costs, } \\
\text { energy and environmental impact of sourcing and refining } \\
\text { every raw material or processed component of a } \\
\text { manufactured item. }\end{array}$ & $\begin{array}{l}\text { It includes both LCA and LCC. } \\
\text { Requires a license. }\end{array}$ & 4 \\
\hline SimaPro & $\begin{array}{l}\text { SimaPro is a tool to collect, analyse and monitor the } \\
\text { sustainability performance data of products and services. } \\
\text { SimaPro can model and analyse complex life cycles in a } \\
\text { systematic and transparent way and quantify the } \\
\text { environmental impact of products and services across all life } \\
\text { cycle stages. }\end{array}$ & $\begin{array}{l}\text { SimaPro is a LCA software } \\
\text { package that been in use for } \\
25 \text {-years in more than } 80 \\
\text { countries. } \\
\text { There is a variety of licences. }\end{array}$ & 5 \\
\hline Renobuild & $\begin{array}{l}\text { Renobuild is a tool for evaluating the sustainability of } \\
\text { renovations. It provides support for discussions and decision } \\
\text { making by systematically comparing the effects of alternative } \\
\text { renovation scenarios. It can be used to evaluate different } \\
\text { alternatives. }\end{array}$ & $\begin{array}{l}\text { Designed especially for } \\
\text { renovation. } \\
\text { Easy to use } \\
\text { In Swedish only. }\end{array}$ & 6 \\
\hline OPERA/MILP & $\begin{array}{l}\text { LCC optimisation software - OPtimal Energy Retrofit } \\
\text { Advisory-Mixed Integer Linear Program (OPERA-MILP) } \\
\text { obtains the cost-optimal energy renovation strategy } \\
\text { corresponding to the lowest building LCC. Based on a pre-set } \\
\text { period ( } 50 \text { years) it considers costs of building maintenance, } \\
\text { investment cost for heating system, energy efficiency } \\
\text { measures on the building envelope, and energy supply. }\end{array}$ & Not publicly available & 7 \\
\hline LCAbyg & $\begin{array}{l}\text { LCAbyg is a tool that calculates life cycle assessments for } \\
\text { buildings. LCAbyg calculates a building's environmental profile } \\
\text { and resource consumption. Based on information about the } \\
\text { building parts the tool calculates the LCA and gathers the } \\
\text { results in a report. }\end{array}$ & $\begin{array}{l}\text { Easy to use } \\
\text { In Danish }\end{array}$ & 8 \\
\hline
\end{tabular}




\begin{tabular}{|c|c|c|c|}
\hline $\begin{array}{ll}\text { Danish } & \text { national } \\
\text { guidance } & \end{array}$ & $\begin{array}{l}\text { LCA guidance for renovation } \\
\text { "Branchevejledning i LCA ved renovering" }\end{array}$ & In Danish & 9 \\
\hline $\begin{array}{l}\text { Swedish national } \\
\text { guidance }\end{array}$ & $\begin{array}{l}\text { LCA guidance for buildings } \\
\text { "Vägledning i LCA för byggnader" }\end{array}$ & In Swedish & 10 \\
\hline RIBuild & $\begin{array}{l}\text { The EU project RIBuild has developed tools for probability } \\
\text { based LCA and LCC for internal insulation of historic masonry } \\
\text { constructions. }\end{array}$ & & $\begin{array}{l}11, \\
12\end{array}$ \\
\hline $\begin{array}{l}\text { The International } \\
\text { EPD System }\end{array}$ & $\begin{array}{l}\text { A global programme for environ-mental declarations based on } \\
\text { ISO } 14025 \text { and EN } 15804 \text {. The online database contains more } \\
\text { than thousand EPDs for a wide range of product categories in } \\
45 \text { countries. }\end{array}$ & $\begin{array}{l}\text { Based on international } \\
\text { standards with national } \\
\text { adaptations. }\end{array}$ & 13 \\
\hline $\begin{array}{l}\text { IEA EBC Annex } 72 \text { - } \\
\text { Assessing Life Cycle } \\
\text { Related } \\
\text { Environmental } \\
\text { Impacts Caused by } \\
\text { Buildings. }\end{array}$ & $\begin{array}{l}\text { This project aims to establish a common methodology with } \\
\text { regionally differentiated guidelines and tools and to develop } \\
\text { national or regional databases with regionally differentiated life } \\
\text { cycle assessment data. }\end{array}$ & $\begin{array}{l}\text { Work in progress. The project } \\
\text { will be concluded in } 2021 .\end{array}$ & 14 \\
\hline
\end{tabular}

1 https://standards.cen.eu/dyn/www/f?p=204:110:0::.:FSP_PROJECT:31325\&cs=16BA443169318FC086C4652D797E50C47

2. https://www.oneclicklca.com/

3. http://www.iea-annex56.org/index.aspx?MenulD=4\&SubMenulD=18

4. http://www.gabi-software.com

5. https://simapro.com/

6. www.renobuild.se

7. Milić, V., Ekelöw, K. and Moshfegh, B. (2018) 'On the performance of LCC optimization software OPERA-MILP by comparison with building energy simulation software IDA ICE', Building and Environment. Pergamon, 128, pp. 305-319.

8. https://www.lcabyg.dk/

9. https://www.lcabyg.dk/publications

10. https://www.boverket.se/sv/byggande/hallbart-byggande-och-forvaltning/livscykelanalys/pdf-generering/?cref=34068

11. https://www.ribuild.eu/sites/default/files/media/RIBuild_D5.1_v2.0.pdf,

12. https://www.ribuild.eu/sites/default/files/media/RIBuild_D5.2_v1.0.pdf

13. www.environdec.com

14. https://annex72.iea-ebc.org/ 


\section{HIBERATLAS BEST PRACTICE EXAMPLE [LINK]}

Timber-framed house in

Alsace: a sustainable

\section{renovation using materials}

with low environmental impact.

The house is a former farm, typical from this agricultural area named the Kochersberg, which long provided Strasbourg with wheat. Before intervention, the house was in poor condition. Some damages were already well-known : - differentiel settlement of $12 \mathrm{~cm}$ throughout first and second floor. Indeed, in these traditional timber-framed houses, the kitchen was separated from the rest of the rooms by a stone-wall, called a "Brandwand", that was supposed to stop the spread of fire. In this case, the "Brandwand" was too heavy. - moisture problems in the basement. This is the consequence of several issues : sloping ground level; use of cement coating and organic coating on the interior wall surface of the basement ; pour of a concrete slab on the basement floor ; lack of ventilation. After inspection, some of the wooden beams of the attic floor and some pieces of the framework were mouldered, probably due to a leak in the roof in the early 20 th century. Wall plates from the second storey were also mouldered. Fortunately, those from the first storey were in good condition.

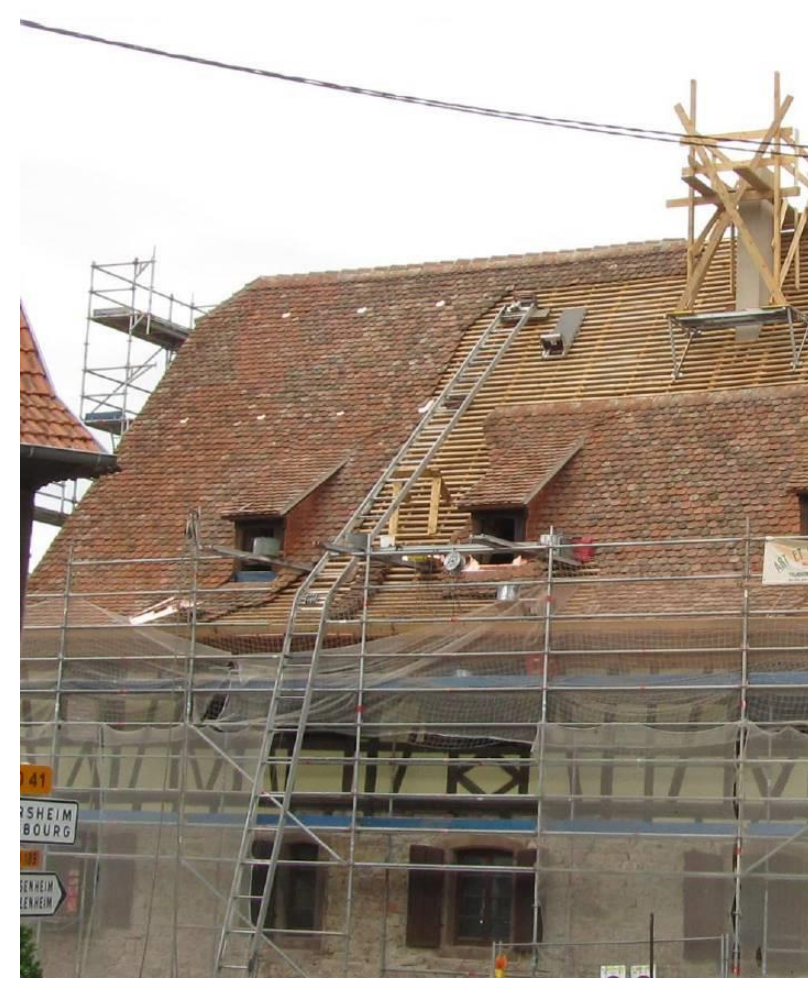

Photos: CEREMA
The owner wanted to restore his house to its original condition, but also to retrofit it and to obtain a low energy label. One particular objective was to prove, by a real example, that it is possible to live in that kind of heritage buildings with all modern conveniences. Finally, the owner wanted to support the local craftspeople that are still working on heritage buildings (joiner, brick maker, traditonnal stove maker, carpenter, cabinetmaker) and the local materials (lime, naturel pigment, wood pellets). The owner had to convince a lot of people that it was possible to retrofit an heritage building like his : - The first architect that he hired declared that it was not possible to insulate his house with lime-hemp. - The architectural review board in Alsace was sceptical about double-glazing windows made to measure, until he saw the prototyp. - Many people thought that creating a technical room by underpinning was impossible.

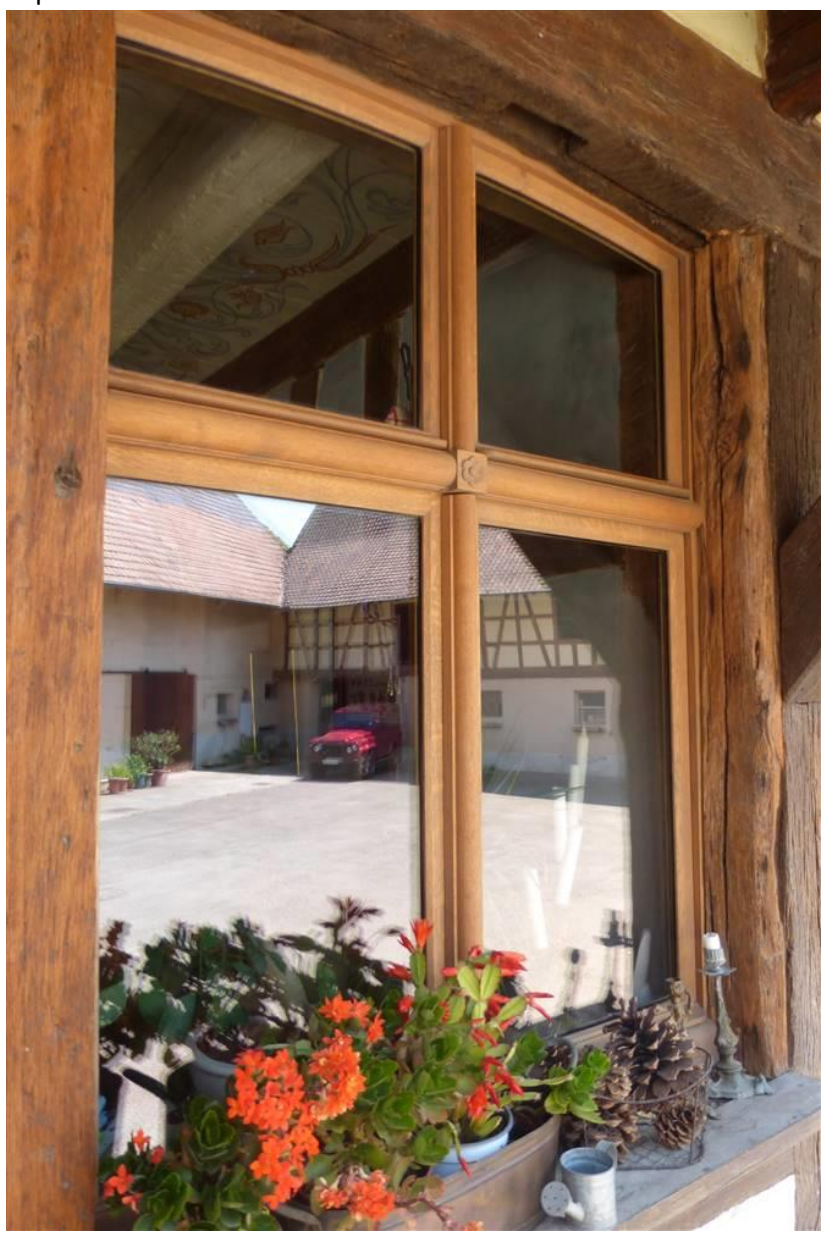

Implemented energy efficiency measures

Walls:

12 to $18 \mathrm{~cm}$ of lime-hemp concrete was sprayed on walls. A dew point analysis was performed for walls, as well as for basement ceiling and attic floor, to validate the choice of this insulating material. The project team was aware that the post-intervention U-value was not as good as it should be, but decided to compensate on other elements. Lime-hemp concrete was chosen because it is permeable to vapour and that it has so a similar behaviour to cob. Besides, lime-hemp concrete increases the sensation of comfort of the occupants, what was one of the objective of the owner. 
U-value: pre intervention $1,75 \mathrm{~W} / \mathrm{m} 2 \mathrm{~K}$, post intervention $0,39 \mathrm{~W} / \mathrm{m} 2 \mathrm{~K}$

\section{Windows}

All the original single-glazed wooden windows were replaced by double-glazed ones. Thanks to pictures from the beginning of the 20th century, it was possible to restore the windows as they were originally. The doors were replaced by more traditional ones. The outside shutters are the original ones. A loggia was created in the second storey by removing cob from timber-frame and installing a doubleglazed fixed window against the interior surface of the wall. This brings light to the house, knowing that these traditional houses are often depreciated because of their lack of light. The windows are all in oak and some are arched. They are made of four casements that can be opened independently.

U-value: pre intervention $4,0 \mathrm{~W} / \mathrm{m} 2 \mathrm{~K}$, post intervention 2,4 $\mathrm{W} / \mathrm{m} 2 \mathrm{~K}$

Roof

The tiles were replaced by traditional ones, called "Biberschwanz" (beaver tails). A rain screen, that was not originally present, was installed. The roof windows were replaced by dormers, which shape is more traditional. Modern roof vents were also replaced by more traditional ones in copper. After installing a vapour retarder, the attic floor was insulated with about $9 \mathrm{~cm}$ of granulated cork (in order to get the floor horizontal) and with two cross-coats of wood-fibre panels of $10 \mathrm{~cm}$. The top of the stairwell was insulated with $20 \mathrm{~cm}$ of granulated cork and $4 \mathrm{~cm}$ of woodwool.

U-value: pre intervention $0,95 \mathrm{~W} / \mathrm{m} 2 \mathrm{~K}$, post intervention $0,16 \mathrm{~W} / \mathrm{m} 2 \mathrm{~K}$

HVAC

A $25 \mathrm{~kW}$ pellet boiler of an efficiency of $95 \%$ was installed in the technical room. It provides heating and domestic hot water thanks to two storage tank (300 and $800 \mathrm{~L}$ respectively). The pellet silo is also stored in the technical room. At the beginning of the project, a geothermal heat pump was first considered but rapidly abandoned because of the high cost of it and technical issues. A traditional stove, called "Kachelofe", was installed in the heated envelope as an additonal heating.

The renovation shows that it is possible to use materials with low environmental impact and still achieve a low energy use. By changing the heat source to biofuels the greenhouse gas emissions related to energy use is lowered. The chosen constructions and materials fit well together with the historic fabric, both from a technical and a heritage preservation point of view.

\subsection{Economic viability}

Let's face it: cost is often the most decisive factor in refurbishment projects. We cannot plan innovative, environmentally friendly and customized solutions of high quality if there is no funding for it. The planning must therefore be realistic and based on the financial resources available.

The good thing is that while the investment cost can be high, there is often a high return on the investment - making the costs low in the long run. This reinforces the argument for putting a lot of effort into the planning process. By implementing interventions of high quality that facilitate a sustainable function of the building, there will be revenues from its use, and savings from a reduced energy consumption.

In all professional organizations there are established procedures for how to manage economic aspects. Historic buildings do not need special treatment in this respect. However, there are aspects that have an indirect effect and should be taken into account. There can be a larger uncertainty regarding the cost of interventions, as well as regarding the energy savings. Standard calculations and cost models might not be applicable.

The difference in time perspectives between preservation and common economic investments is striking. While investments often are expected to pay back after 10 years or so, preservation is usually thought of as something that should make buildings last for centuries. Managing historic buildings shouldn't be about making short term profits. Try to use low discount rates, long payback times and argue for that buildings, well maintained and energy efficient, are low-risk and long-term investments.

\section{Assessment criteria}

- Life cycle cost

- Investment cost

- Operating cost (savings!)

Recommended minimum level of assessment:

- Calculate life cycle cost through with a simplified model (e.g. payback time)

- Estimate if the investment is realistic given the project budget 


\section{PART 5 SELECTING MEASURES}

Having done all the groundwork, it is now time to identify appropriate energy-efficiency measures. This should be done in a systematic and iterative way in order not to overlook any possible measures. The work starts with a creative inventory phase, where a "long list" of measures is identified. From this list, a set of measures relevant for the project are quickly identified: the "short list". It will also help to ensure that measures are properly integrated and technically compatible.

Who should be involved in the selection process? Also this procedure is interdisciplinary, and will often require many different professional competencies. It is important that relevant expertise is used where needed. It is a good idea to draw on the experience of the whole project team in initial steps where potential measures are identified. The more disciplinary assessments of measures can be done individually. In the final step, where the actual decision-making is done, should again be in a larger group where both stakeholders and experts are present.

\section{LibraRy - SELecting Measures 1}

To identify the short list the planning group gathers for a meeting. Boel has prepared a long list of measures based on online resources (HiBERtool and the Responsible retrofit guidance wheel). The group members are tries to come up with additional potential measures based on previous experience, but this time there are no more options added. By systematically going through the long list of measures, the group identifies a number of potentially attractive measures. The ones that are discarded are measures that for some obvious reason are not appropriate, acceptable or applicable. After a couple of hours of intense discussions the group have identified 15 different measures related to the building envelope, energy sources, heating system, ventilation system and change of use. The task to assess the chosen short list of measures is distributed to the group members, depending on their expertise.

In this project, all measures are quantitatively assessed in terms of energy savings and economic viability. While some measures, like adding insulation to the roof joists and replacing old technical equipment, require little efforts to be assessed, there are others that are more ardous. Internal insulation is quickly identified as one measure that has to be assessed in detail, as there is much uncertainty about the impact on several assessement criteria. It is decided that the moisture risk assessment will be outsourced to a consultancy firm, and that there is a detailed assessment being made of the impact on heritage values in the various rooms. 


\section{HIBERTOOL BEST PRACTICE EXAMPLE [LINK]}

\section{Replacing the inner glass of windows}

\section{Author: Dagmar Exner}
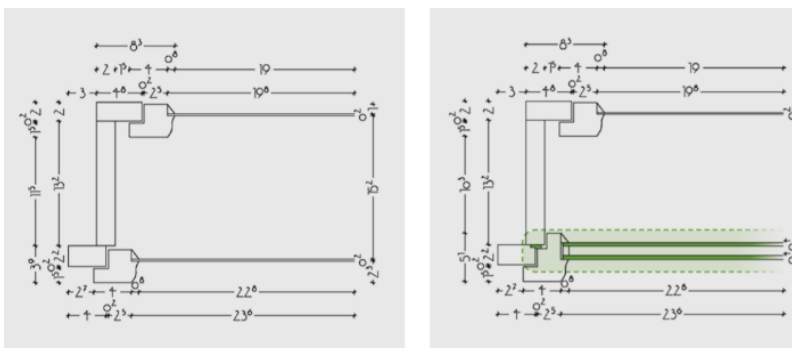

Horizontal section before and after retrofit

Replacing the inner glass of a window can be used for constructions with several window layers (one behind the other), such as coupled or box-type windows. The historic window construction including window frame and outer glazing is conserved and restored. The solution foresees to replace the historical inner usually single glass panes with insulating glass or vacuum glazing. In order to fit insulating glazing, the rabbet and/or frame of the inner window often has to be enlarged on the outer side with a wood lath. The Ug-value can be improved significantly and the historical appearance from outside can be preserved. It must be ensured that the existing hinges can bear the additional weight of the new glazing.
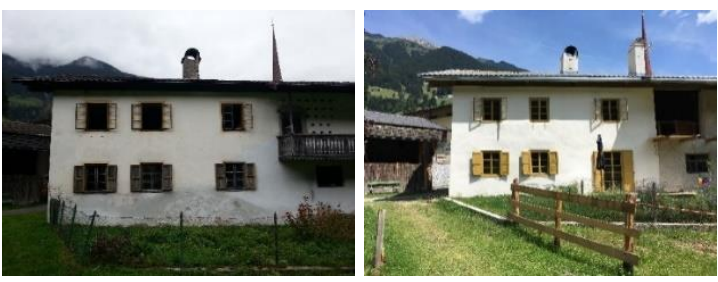

West view of Knablhof before and after retrofit

The Knablhof is a residential house located in Mareit in South Tyrol (North Italy) on a sea level of about $1.000 \mathrm{~m}$. The building is very characteristic for the village. Built in 1819 it is one of the oldest buildings of the village in the village center. It was built as former chandlers' house with a connected barn and stable. Before the renovation, the house was uninhabited for 40 years. The heritage preservation office has formulated clear requirements for the building, which is under monument protection, which were taken into account during the retrofit. Conservation requirements with regard the windows: "Preservation of the historic window construction, (an energetic upgrading is possible): wooden windows with sash bars and slender window frame dimensions, drip sill (Wetterschenkel) on the below side of the frame in wood. Window colors in ochre with linseed oil paint, preservation of room layout, retention of size and frame proportions, replacement of one window into a window door is possible."
In the case of the windows of the Knablhof, the historic window construction consisted of box-type windows from $1930 / 34$. Airtightness of the windows was improved by milling a groove and integrating a seal on the inner side of the window frame. To reduce transmission heat losses, the single glazing of the inner window sashes was substituted by a double-glazing. So that the historical narrow frame can hold the thicker glazing pane, it was reinforced on the outside by a wooden strip (see drawing). The insulating glazing was fixed again on the outside with putty (of linseed oil). The window frames were restored on-site by renewing the paint with linseed oil. The outer window sashes are painted with linseed oil paint in ochre according to the specifications of the monument office, while the inner window sashes are not painted with linseed oil paint as there is a risk that the linseed oil could damage the butyl of the insulating glass. Damaged outer panes were repaired with intact historical inner panes. Thus, all exterior windows have exclusively historical glazing.
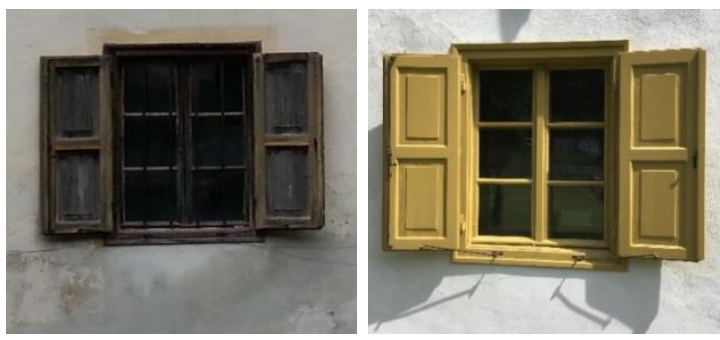

Knablhof (box-type window) - before and after renovation

When renovating the box window with this method, care must be taken to ensure that the seal of the inner window is done in an accurate way. At the same time, the outside window must be well ventilated enough to be able to remove moisture in the space between the panes. If room air enters the window cavity, the risk of condensation is high. The window manufacturer used a system from Zoller-Prantl for the renovation. The special gaskets patented by the company enable even warped window frames to be closed completely airtight. Thus, no humidity can penetrate the interior of the box window.

The retrofit solution corresponds to the requirements of the heritage authority preserving the historic window construction and respecting all other criteria on color and proportions. Visual changes were foreseen only on the inner view on the window: the replacement of the historic single glazing in the inner window sashes into the thicker doubleglazing with better energy performance required the enlarging of the inner window frames with a wooden strip. Besides that, the float double-glazing has another optic than the historic glazing. The integrated seal on the inner side of the window frame is only visible when the inner window sashes are open. Thus, the window appearance and proportions didn't change at all from the outside and only slightly on the inside. Moisture safety: The window construction after retrofit is generally moisture safe. Through the double-glazing in the inner window sashes, we have higher surface temperatures on the pane and thus less condensation risk. Surface temperatures in the angle between window frame and reveal are already higher in case of a box-type window. In case of the Knablhof interior insulation in the window reveal, avoids additionally 
condensation all around the window frame. The window manufacturer used special seals and a special manufacturing of the grooves which make it possible to make even slightly warped window frames completely airtight. Thus, no vapor can penetrate into the intermediate space between the two-window layer and condensate on the inner surface of the outer glazing. Energy improvement: Ventilation heat losses through leaky windows were decreased by improving the airtightness through a seal on the inner side of the window frame and between the two inner window sashes. Transmission heat losses were decreases by the exchange of the inner glazing into a double-glazing $\left(\mathrm{Ug}=1,10 \mathrm{~W} / \mathrm{m}^{2} \mathrm{~K}\right.$ after; $\mathrm{Ug}=5,75 \mathrm{~W} / \mathrm{m}^{2} \mathrm{~K}$ before); the overall Uw-value was thus improved from 2,36 $\mathrm{W} / \mathrm{m}^{2} \mathrm{~K}$ to $1,26 \mathrm{~W} / \mathrm{m}^{2} \mathrm{~K}$.
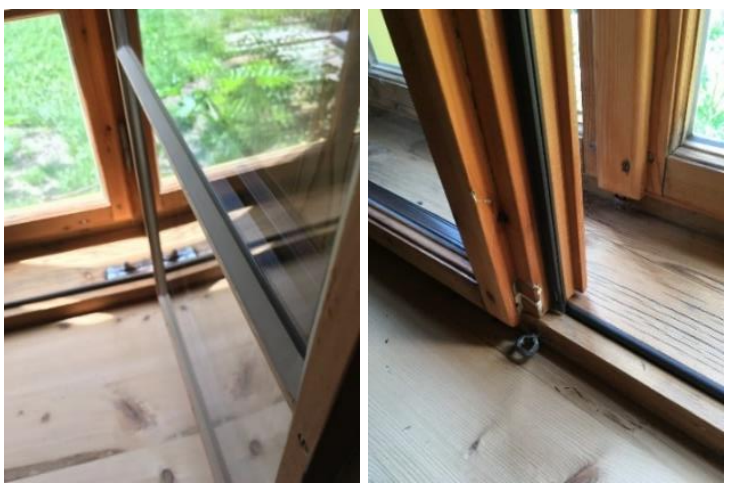

Knablhof (box-type window) - details after renovation

\section{Pros and Cons}

Pros: - in case of a box-type window the two window layers allow to intervene on the inner window layers for energy enhancement, the view from outside can be completely preserved - with this solution great parts of the window construction can be preserved (all wooden parts) and is only slightly changed. Historic glazing on the outer window layer is preserved, too. - at the same time energy performance can be improved significantly (Uw-value after retrofit 1,26 $\mathrm{W} / \mathrm{m}^{2} \mathrm{~K}$ )

Cons: - the inner (energy efficient) window layer has to be widely airtight - the seal has to compensate also uneven or slightly curved window frames - the outer window layer has to be "untight" or well ventilated enough - both in order to avoid condensation risk on the outer window layer

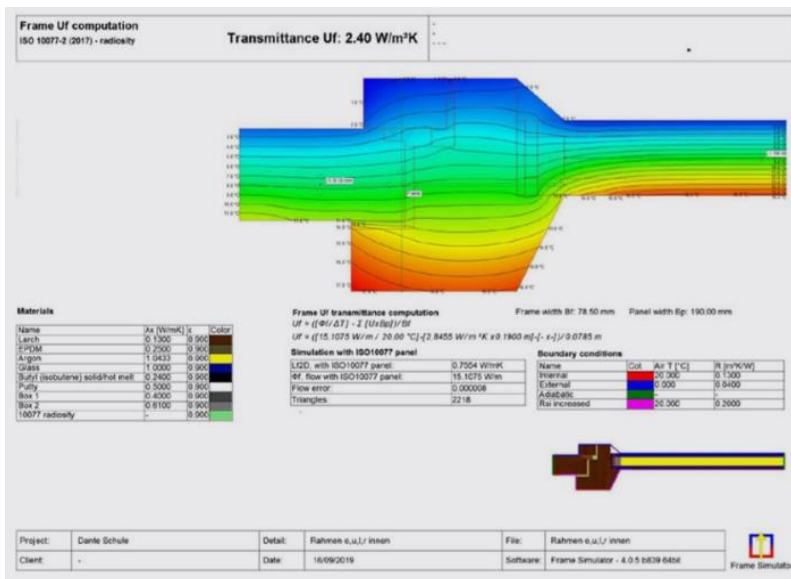

Calculation of Uf-value of the inner window sash after retrofit

\begin{tabular}{|l|l|l|}
\hline $\begin{array}{l}\text { Thermal } \\
\text { properties }\end{array}$ & Existing window & $\begin{array}{l}\text { Refurbished } \\
\text { window }\end{array}$ \\
\hline Window type & Box-type window & Box-type window \\
\hline Glazing & $\begin{array}{l}\text { Inner window: } \\
\text { single glazing } \\
\text { Outer window: } \\
\text { single glazing }\end{array}$ & $\begin{array}{l}\text { Inner window: } \\
\text { double glazing } \\
\text { Outer window: } \\
\text { single glazing }\end{array}$ \\
\hline Shading & $\begin{array}{l}\text { Without/window } \\
\text { shutters }\end{array}$ & $\begin{array}{l}\text { Without/window } \\
\text { shutters }\end{array}$ \\
\hline Uw & 5,0 & 5,0 \\
\hline Ug & 1,4 & 1,4 \\
\hline Uf & 0,6 & 0,6 \\
\hline g-value glass & No sealing & $\begin{array}{l}\text { Zoller-Prantl } \\
\text { sealing }\end{array}$ \\
\hline Air tightness & 2017 \\
\hline $\begin{array}{l}\text { Approximate } \\
\text { installation } \\
\text { year }\end{array}$ & $1819,1930-34$ & \\
\hline
\end{tabular}




\subsection{Identify the long list}

The outcome of this step should be a comprehensive list of possible measures. The idea here is to be sure of that no potential measures are excluded beforehand. The long list can be created based on a previous inventory, but can also be the result of an interdisciplinary brainstorming exercise.

If a generic list is used, make sure that it is up to date and relevant for the specific project. Energy efficiency measures are here defined in a wide sense, including measures to the building envelope, technical systems, user behaviour and microgeneration. The list can be based on EN 16247-2 Energy audits - Part 2: Buildings.

\section{Resources}

\section{- HiBERtool}

- Responible Retrofit Guidance Wheel

- EN 16247-2 Energy audits - Part 2: Buildings.

- Troi A., Bastian Z., 2015. Energy Efficiency solutions for historic buildings: a handbook, Birkhäuser, Basel.

\subsection{Identify the short list}

With the comprehensive list of measures from the previous step, it is now time to identify a "short list" of plausible measures that should be evaluated further. Measures that for some reason are obviously not appropriate should be excluded from the long list. The idea is to make an interdisciplinary assessment early to save time and resources later. For example, if a measure clearly will not be acceptable from a heritage preservation point of view, there is no need to proceed with sophisticated and resource-demanding analyses of energy savings: - the measure will not be implemented in the end no matter how much energy is saved.

\section{Success factors for the selection of} measures

$\checkmark$ Utilize the capacity of the whole project team for identifying possible measures

$\checkmark \mathrm{Be}$ open-minded to non-standard measures in the initial phase

$\checkmark$ Don't overdo the assessment, start with the simple things to exclude unrealistic measures. Use sophisticated assessment methods only when it is needed.

$\checkmark$ Keep the whole building in mind. Avoid suboptimization of measures. Are individual investments realistic when looking at the overall budget?

$\checkmark$ Build on existing procedures. If there are established routines that work well, do not invent the wheel.

$\checkmark$ Consult experts when needed. Do not attempt to perform assessments without necessary competence.

$\checkmark$ Follow the law. Start with excluding measures that are not according to legislation (including heritage law).

This should not be a time-consuming step, rather, it is a "gatekeeper" where the planning team's previous experience and interdisciplinary expertise is used to quickly exclude inappropriate measures. Do not let the best be the enemy of the good. This should be a quick assessment, so don't put too much effort on assessing measures that are unrealistic. Still, it is recommended to document the selection process, and give a brief justification for each decision. 


\section{HIBERTOOL BEST PRACTICE EXAMPLE [LINK]}

\section{An innovative aerogel-based wallpaper}

\begin{abstract}
Author: Sara Mauri
The solution is a super-insulating aerogel-based textile wallpaper that can be installed on the inner side of perimeter walls. The innovative wallpaper is based on two completely independent layers with an air gap of about $2 \mathrm{~mm}$ in between, combining properties of advanced technical textiles and high-performance insulating materials in few $\mathrm{mm}$ of thickness. As a matter of fact, the system is composed of a layer made of a porous, flexible support impregnated with silica aerogel glued to the existing wall, forming the insulating core, and a finishing textile layer. The latter can be easily installed and replaced thanks to a simple tensioning device, consisting of a system of plastic zips fixed to the wall on one side and then connected to the finishing layer on the other side. The top connection, fixed to the wall with nails and/or glue, is based on a PVC strip carrying a plastic zip with a slider on one edge. At the bottom of the wall, the plastic zips are applied on the finishing textile by means of a thermoadhesive tape that is ironed on the fabric.
\end{abstract}

The wallpaper system was developed as part of the European project EASEE (Envelope Approach to improve Sustainability and Energy efficiency in Existing multi-storey multi-owner residential buildings). Although this research project did not consider historical buildings, the system characteristics of easy assemblage/dismounting for periodic use, flexibility, reversibility, not destructiveness, lightness, small thickness, also meet the requirements of the intervention of historic buildings. This textile wallpaper represents a technologically improving of a tapestry, a solution coming from the past traditionally used to mitigate the effects of the lower wall temperatures. The improvement due to the textile is valuable, considering the amount of square meters that could reduce the thermal exchange with the colder surface underneath. Therefore, the new wallpaper system decreases the surface temperatures with the advantage to avoid any permanent, invasive, destructive, irreversible intervention. The thermal performances of the new textile wallpaper were compared to other two internal thermal insulation systems, traditional in terms of installation process: they are wet assembled, thicker than the new textile wallpaper, not reversible (advanced insulated perlite board; Laminated panel composed of silica aerogel impregnated unwoven fibrous blankets fixed to a rigid support). The results of the tests showed that the performances of the textile wallpaper are comparable with the one of the interior traditional insulation. As a matter of fact, the insulating layer that composed the system presents the following thermal behaviour: average thermal resistance $R=0.125 \mathrm{~m} 2 \mathrm{~K} / \mathrm{W}$; thermal conductivity $\lambda=0.036 \mathrm{~W} / \mathrm{mK}$. Moreover, the solution was defined "permeable insulating wallpaper" because it is open to water vapour diffusion, a crucial aspect from the point of view of building physics.
The chosen test wall for the installation of this inner retrofitting system is part of an eight-storey building called "La Nave" (building $\mathrm{n}^{\circ} 14$ ), situated at the Leonardo University Campus of Politecnico di Milano. The building was designed by Gio Ponti, a famous architect active from the Twenties to the Seventies, and hosts classrooms and teachers' offices. It was built in 1965 and classified as Cultural Heritage in 2007. "La Nave" is composed of a concrete and steel structure and the façade is an unventilated cavity wall. The latter, from outside to inside, is composed of: vitrified grey ceramic tiles (dimensions: $15 \mathrm{x}$ $7,5 \times 0,7 \mathrm{~cm})$, cement base render $(2,5 \mathrm{~cm})$, first layer of hollow bricks ( $12 \mathrm{~cm}$ thick), an unventilated air cavity ( 34,5 $\mathrm{cm}$ thick), second layer of hollow bricks ( $8 \mathrm{~cm}$ thick) and internal cement lime based plaster with gypsum finishing $(1,5 \mathrm{~cm})$. The whole thickness of the wall before retrofit is $59.2 \mathrm{~cm}$. It represents the typical massive construction with a low level of thermal insulation as many constructions of that time. The portion of the wall retrofitted is placed at the second floor, South-East and South-West oriented and belong to a meeting/teaching room. The inner surface covered by the wallpaper system is $3,37 \mathrm{~m} 2$, with a $7 \mathrm{~mm}$ thickness. The insulation layer was glued to the existing wall with a breathable mineral mortar and the finishing layer was the applied in front of the insulation with a bespoken tensioning system.

\section{PROS:}

- Low thermal conductivity $(\lambda=0.036 \mathrm{~W} / \mathrm{mK})$;

- Thin and lightweight solution

- Controlled fire behaviour

- Water vapour permeability

- Mitigates the effect of the cold surface of the wall

- Ease of transportation and storage

- Ease of installation because all the assembly operations can be performed with common tools (scissors, cutter, hammer and flatiron)

- Insulation layer glued to the existing wall like a standard wallpaper

- Finishing layer completely dry-assembled and removable for any reason (like washing, substituting a failing element, improving the performances or simply changing the appearance of the wall)

- Geometrical adaptability which allows the application on (not always planar) existing walls, following their forms also in correspondence of the corners, thanks to the physical flexibility of all the components.

CONS:

- Applicable only as indoor insulation solution

- Potential thermal bridging and condensation issues

- The use in historic buildings may be restricted due to existing important decorations (i.e. wall paintings)

- High costs of the aerogel material. 


\subsection{Assessment of measures}

The assessment of energy efficiency measures is the most crucial step in the whole planning process, and all the preceding steps underpin and inform the assessment carried out here. The amount of work put into this step will vary with each project. Assessments made in some high-profile projects will resemble or be part of research projects. Smaller projects might use heuristics or back-of-the-envelope calculations. However, too complex or too simplified assessments should be avoided: the requirements, resources and ambitions with the project should determine the level of sophistication.

The basic principle for the assessment is to evaluate the impact of single measures, then combine measures into packages, and finally assess the packages. It is important to understand that the assessment is an input to the decision-making process, it is not a mechanical way of prioritizing among different measures.

The assessments should be guided by the objectives of the individual project. Legal requirements should of course always be fulfilled. Essentially, the assessment is a risk and benefit analysis. An energy efficiency measure might cause risks related to the technical compatibility, such as increased risk for mould growth. It might also cause risks related to the heritage significance, such as when a historic window is replaced with a replica. All measures will require an investment cost. On the other side of the equation there are different kinds of benefits, such as improved use, lowered environmental impact or lowered running costs.

A convenient way to perform the assessment is to use a spreadsheet with all the individual measures from the short lista and all the assessment criteria. A traffic light system (red, yellow, green) can be used for all the criteria, but quantitative values should also be used when possible (see an example in the library case study).

\section{Library - Selecting Measures 2}

About a month later, the group gathers again to do a holistic assessment of the measures, now backed up with calculated estimates on energy savings and costs, as well as an moisture risk analysis related to the internal insulation. An assessment table is used where a number from 1 to 5 is jointly decided for each criteria. 1 is worst, meaning unacceptable (no benefit/high risk), and 5 is best (no risk/high benefit). In addition to the table, there is also a calculation of the total energy savings and cost for a number of packages of measures.

There are a number of measures which all have low risk and low to high benefit. These are easily distinguished as appropriate. The same is true for a few measures with high risk, either in terms of technical risk or threatening heritage values. The delicate question for the planning team is what to do with the measures in-between, with some risk but also high benefit. There is also a matter of cost. The budget for the project is not yet finally decided.

The meeting ends with a few unresolved issues: Is it possible to exchange some of the windows that are not original? (a dialogue with the heritage authorities is needed), is there enough funding to install the relatively expensive internal insulation system? (a dialogue with the politicians is needed). The intended used as office space for some rooms facing south will lead to problems with overheating, how to deal with that? (a revision of the objectives is needed).

After a few weeks of more meetings and revisions of the original objectives, the planning group can finally agree on a package of energy efficiency measures to be integrated into the refurbishment of the building. The process of getting building consent turns out to be straightforward, thanks to the thorough work based on a detailed multidisciplinary understanding of the building and its use, the well motivated suggestions and the early collaboration with the heritage authorities.

\subsection{Combining multiple measures}

There will generally be several measures implemented in the building at the same time. It is therefore important to consider how combinations of individual measures affect the assessment. Synergies of packages are mainly related to energy use and indoor climate, LCA and LCC. The energy savings or costs of measures to the building envelope, heating 
system, ventilation system and use of the building cannot just be added.

A common example is that changing the heat source might affect the cost-effectiveness of measures to the building envelope. Using solar heating or geothermal heat pumps will lower the running costs and make insulation measures less cost-effective. Another common example is that a changed use of the building might affect the indoor temperature, and in turn the estimated savings from other energy efficiency measures.

Packages of measures can be "optimised" from a techno-economic point of view using LCC or LCA. These packages need to be assessed in relation to other objectives, such as heritage value, in a final holistic assessment. Examples of how this can be carried out both at the district and the indidvual level is shown below.

\section{CASE STUDY ON THE OPTIMISATION OF PACKAGES}

This section exemplifies the aforementioned approach and discussion in the case of a one family, wooden building from the late 19th century in the Swedish capital of Stockholm. It is not formally protected which means that there is a wide room for negotiation on what type of measures that can be accepted. The Swedish Planning and Building Act mandates, without specifications, that renovations in all buildings, no exceptions, should be carried out carefully with respect to the heritage values.

In this case study the energy savings targets used were 20 $\%$ and $50 \%$, corresponding to different targets used in EU and Sweden (Broström et al., 2014)

Based on a gross list of the most common energy efficiency measures in Sweden, a first assessment was made of risks and benefits in relation to the particular building. This step was mainly meant to exclude inappropriate measures and to define a range of acceptable measures. The assessment was carried out by a multidisciplinary group of experts. Based on existing knowledge and experience each measure was assessed with respect to energy savings, economic return, impact on heritage values, durability, moisture risk and effect on the indoor environment.

In the next step, a more detailed assessment was made on a short list of measures. The basic tool for selecting measures was a program for life cycle cost (LCC) optimisation (Liu, Rohdin, \& Moshfegh, 2018). Using a database with costs and technical specifications for different measures, the program defines a combination of measures that would give the lowest life cycle cost.
The LCC optimisation resulted in the combination of measures that would achieve the given targets at the lowest LCC. The $20 \%$ target could be reached with measures that had little or none effect on heritage values such as weather stripping, heat pumps and attic insulation. In this case LCC was reduced by $15 \%$ (Broström et al., 2014).

In order to reach the national $50 \%$ target, exterior wall insulation and window replacement was necessary, in addition to less intrusive measures. In this case, LCC was reduced by $23 \%$. If the exterior insulation and window replacement are excluded in the LCC optimisation, the energy saving would be reduced to $29 \%$ and LCC would be reduced by $16 \%$ (Broström et al., 2014).

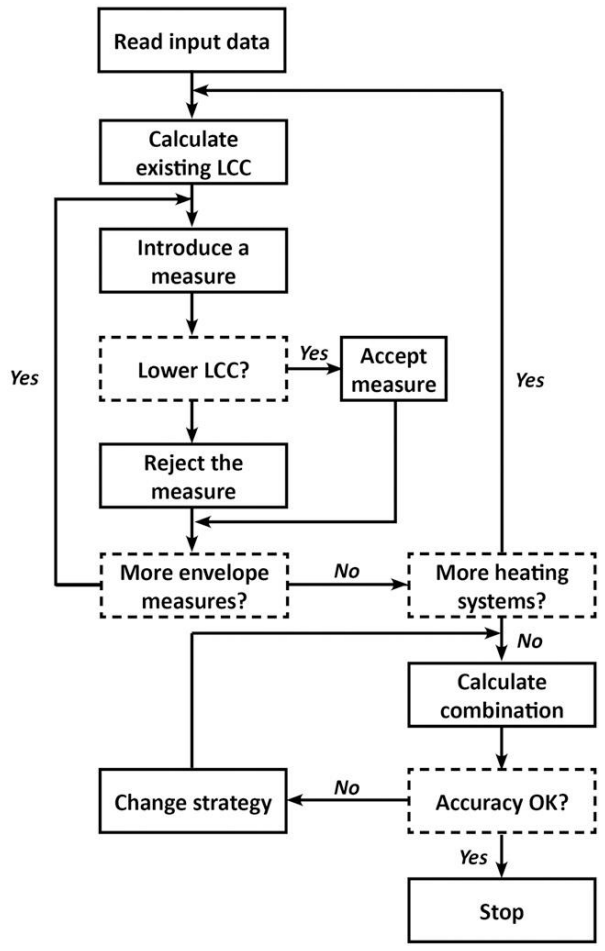

The results illustrate how the method can be used to assess the consequences of polices and plans related to energy efficiency. For this particular building it could be shown that the European $20 \%$ target can be reached without problems. But the more ambitious national target $(50 \%)$ would necessitate measures, such as external insulation and window retrofits, that would change the visual and material character of the building significantly.

The above method allows for an interaction between the quantitative assessment of the techno-economic optimisation and the qualitative assessment of impact on heritage values. Through a multidisciplinary dialogue, stakeholders and experts can arrive at a solution that balances energy conservation and building conservation for a given building. This approach can be used to assess the consequences of national targets for energy savings and let stakeholders and experts, through further iterations, decide on an appropriate level of energy saving in relation to the impact on heritage values. 


\subsection{Decision or iteration?}

When the assessment of individual measures (or packages of measures) is finished, it is time to make a decision. The assessment process should not be understood as a mechanical device that provides an optimised solution. Rather, its purpose is to support decision makers to make a well-balanced and informed decision.

Energy efficiency measures with high risks (either technical risks or risks to the heritage values) should generally be avoided. Measures with no risk and some benefit should generally be implemented. The difficult question is to decide on measures that potentially imply some risk, but also have high benefit.

\section{The Farmhouse: Selecting Measures}

Andrea uses her professional network to involve an energy expert in the process to select energy efficiency measures. As a basis they have the previously issued energy certificate. Together they discuss previous projects and consult online resources to get inspiration for new and innovative solutions. Based on their discussion the make a long list of possible measures. Some utopian measures are discarded. A discussion with the owners results in an even shorter list. The resulting measures are then assessed in detail.

The energy expert calculates energy savings and costs for the various measures, and Andrea uses a simple list of pros and cons regarding the other critera. After a dialogue with the owners it is realised that all of the initial objectives cannot be met at the same time. The owners have to accept that the implementation of the project will be more costly than their budget. On the other hand, there will be a lower running cost. After discussions with the bank they are granted a bigger loan and they can finally select a package of energy efficiency measures. Given that no big external alterations will be made to the exterior, they are also quickly given building consent and the implementation phase can begin.

In some occasions, it will not be possible to identify any acceptable measures. No options will fulfil the objectives. Then a decision has to made if an iteration in the decision process is necessary. For example: is there a need to revise the objectives? Is there a need to make a more detailed analysis of some aspect? There is nothing wrong with a decision process that takes two steps forward and one step backward, as long as the final outcome is a good one. The other option is to conclude that no acceptable energy efficiency measures were possible to identify. Remember that doing nothing in this case is not to be considered failure, but in fact the best decision based on the particular circumstances.

\section{Further reading for selecting measures}

Marincioni, V., Gori, V., de Place Hansen, E. J., Herrera-Avellanosa, D., Mauri, S., Giancola, E., ... Rieser, A. (2021). How Can Scientific Literature Support Decision-Making in the Renovation of Historic Buildings? An Evidence-Based Approach for Improving the Performance of Walls. Sustainability, 13(4), 2266. https://doi.org/10.3390/su13042266

Polo López, C. S., Lucchi, E., Leonardi, E., Durante, A., Schmidt, A., \& Curtis, R. (2021). RiskBenefit Assessment Scheme for Renewable Solar Solutions in Traditional and Historic Buildings. Sustainability, 13(9), 5246. https://doi.org/10.3390/su13095246

Rieser, A., Pfluger, R., Troi, A., Herrera-Avellanosa, D., Thomsen, K. E., Rose, J., ... Chung, D. (2021). Integration of Energy-Efficient Ventilation Systems in Historic BuildingsReview and Proposal of a Systematic Intervention Approach. Sustainability, 13(4), 2325. https://doi.org/10.3390/su13042325

Historic Scotland Technical papers: Energy Efficiency and Historic Buildings: How to Improve Energy Efficiency, Historic England, 2018

Troi A., Bastian Z., 2015. Energy Efficiency solutions for historic buildings: a handbook, Birkhäuser, Basel.

Webb A., 2017. Energy retrofits in historic and traditional buildings: A review of problems and methods, Renewable and Sustainable Energy Reviews 77:748-759. 


\section{PART 6 IMPLEMENTATION, DOCUMENTATION AND EVALUATION}

\subsection{Introduction}

There is an implicit assumption of EN 16883:2017 that in any given context there are already established processes for implementation, documentation and evaluation. Existing processes and practices will vary greatly depending on the geographic context, tradition and the size of the project. In line with the intentions of the standard, this section elaborates on generic aspects particular to historic buildings in relation to these aspects.

\section{Success factors for the implementation}

$\checkmark$ Explicit goals for the preservation of cultural heritage values transformed into concrete restrictions regarding specific character defining elements

$\checkmark$ Well-functioning communication between contractors, craftspeople and planning team during and after implementation.

$\checkmark$ Dynamic planning - expect the unexpected and be prepared to quickly adapt the planning

$\checkmark$ Assemble a team with experience from working with historic buildings - make sure to have access to external experts

$\checkmark$ Use qualified contractors and craftspeople with experience from working with historic buildings

$\checkmark$ Proactive consultation with relevant authorities

The first and maybe most important addendum to the standard is that without well-functioning processes for implementation, documentation and evaluation the standard will be of limited use.

The suggested division between implementation, documentation and evaluation should not be interpreted as implying a serial process of discrete steps. In practice implementation, documentation and evaluation are continuously integrated.

\subsection{Implementation}

Extra care is needed for historic buildings also during the implementation phase. Most of the qualifications and competence needed in the planning phase will be relevant during implementation. It is wise to have some overlap regarding personnel between planning and implementation, in order to ensure knowledge transfer and continuity. Less experienced clients may need extra support in the transition from planning to implementation.

- The likelihood of unforeseen circumstances is greater in projects involving historic buildings. Perhaps the most common one is that previously unknown or since long forgotten building parts are discovered, and planned interventions have to be revised based on this new information.

- Just like the planning team, the implementation team needs relevant knowledge and know how in relation to the specific project. Knowledge transfer between the conceptual design phase and the later stages of the project is crucial.

- A continued consultation with heritage authorities is recommended, and can be mandatory for listed buildings. 


\section{HIBERATLAS BEST PRACTICE EXAMPLE [ㄴINK]}

\section{Villa Castelli -}

\section{multidisciplinary team with good communication during the implementation phase}

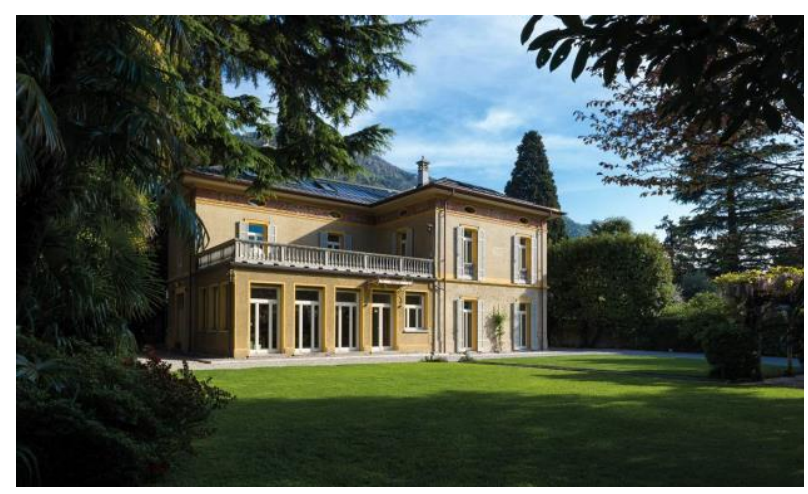

Villa Castelli, Bellani, Italy after the renovation that achieved a $90 \%$ energy demand reduction.

Villa Castelli is a listed building from the 19th century located at the riverside of Lake Como (Italy). The owners set the ambitious goal of renovating the Villa, which had belonged to the family for about 140 years, to the lowest possible energy demand while maintaining the original use of the rooms and the external appearance.
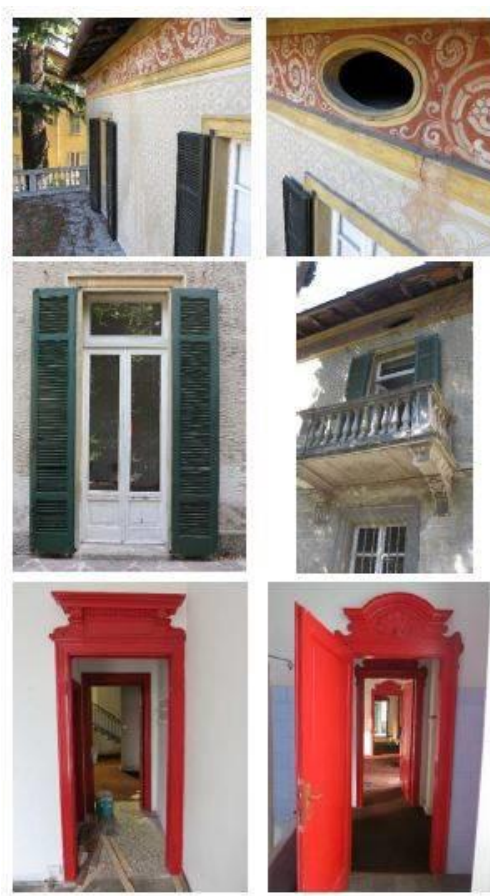
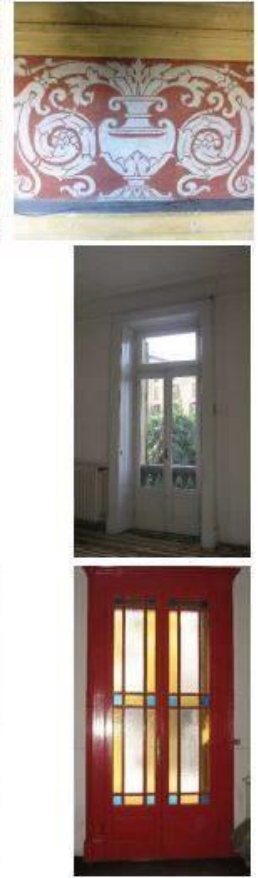

Villa Castelli, Bellani, Italy pre intervention
The general main aim of the renovation was to make the building more usable for the owner family - with a long-term perspective. It was not a matter of smaller measures that improve the comfort a little, but of minimizing the operating costs with a well thought-out comprehensive intervention, optimizing the comfort and usability of the rooms and preserving the charm of the historic building at the same time. The architectural concept followed the path of preserving the existing spatial functions and additionally connecting the often contradictory step-by-step extensions of the rooms of the original building. In addition, structural problems of the building was part of the renovation, some weak points e.g. cracks in the facade had to be analyzed and resolved. The ambitious target for energy efficiency were clearly defined with the client as follows at the beginning of the planning phase

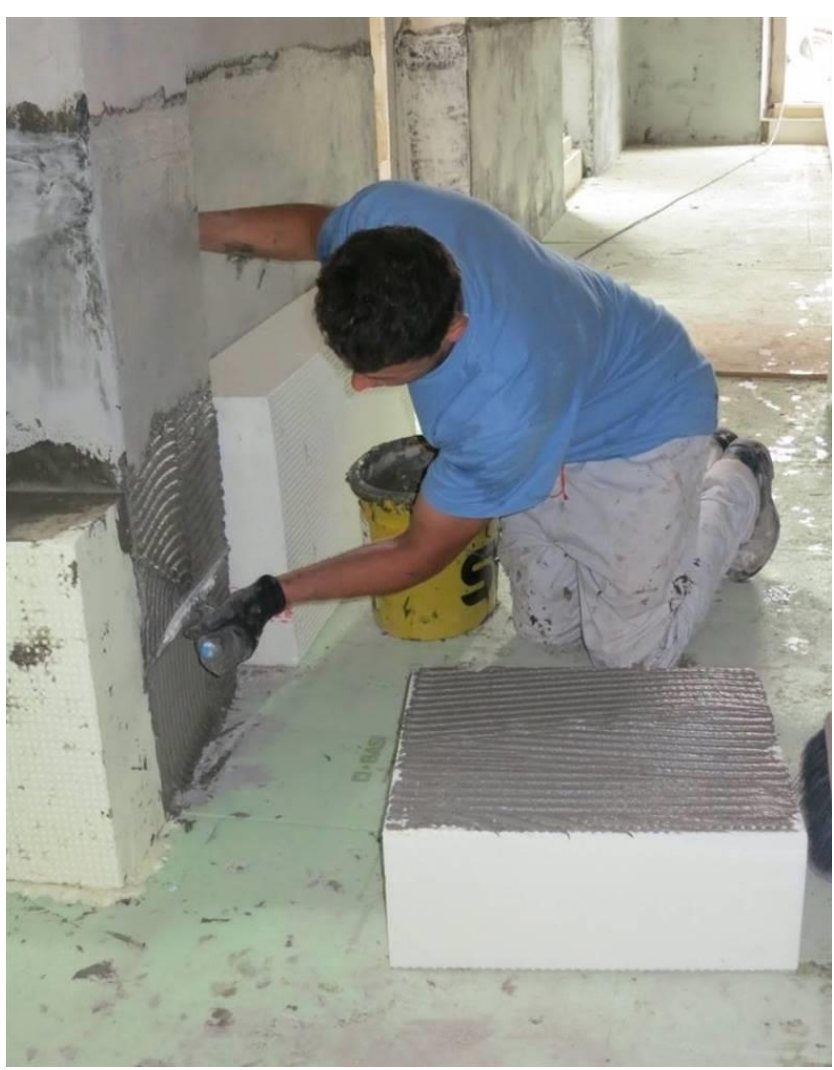

Interior insulation with perlite was installed where possible.Aerogel insulation was used elsewhere.

The whole building retrofit included energy efficiency measures to the building envelope (interior insulation, exchange of windows), HVAC (heat pump, mechanical ventilation with heat recovery) and RES (Photovoltaics). In the end, an energy performance of $28 \mathrm{kWh} / \mathrm{y} / \mathrm{m} 2$ was achieved. During this ambitious and well planned project, it was essential to have a continuous dialogue between a multidisciplinary team also after the planning phase is finishhed. Owners, architect, craftspeople, conservatorrestorers and heritage authorities had a successful collaboration throughout the implementation phase. 


\subsection{Documentation}

Historic buildings often have special requirements regarding documentation of the construction process and the final result. The documentation is a basis for the evaluation of the project, and provides information that can be used in future renovations.

\section{Examples can be:}

- More detailed documentation, as compared to a regular project, of the interventions including drawings and photos. This should include documentation of methods and materials used

- Documentation of new discoveries during the implementation phase

- It is important to keep in mind that the documentation itself will be a historic document. It should be useful for future users in understanding what was done and why. See the building survey section in this handbook for further advice.

\section{Success factors for documentation}

$\checkmark$ The documentation is continuous and an integrated part of the implementation process.

$\checkmark$ Describe not only WHAT was done and HOW but also WHY it was done in a particular way.

$\checkmark$ Use photos and provide enough information about where and when the photo was taken

$\checkmark$ Ensure that there is a well-functioning infrastructure for long-term storage and access of the collected data.

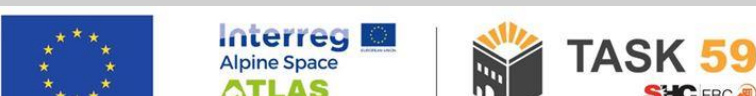 \\ SHCEBC}

\section{Document your project in the HiBERatlas!}

Which buildings are suitable for documentation?

Any building of historic and/or cultural value independent of the level of protection is considered - from medieval buildings over buildings from the 1920s to post WWII architecture.

The basic requirements for good practice examples are:

- Implementation of the project completed

- Renovation of the whole building

- Significant reduction of energy consumption (towards "lowest possible energy demand")

- Evaluation of the heritage compatibility of the solutions

- Available documentation of technical solutions

It is not expected that all these requirements are fulfilled $100 \%$ in every case. If you are unsure whether your project meets all the criteria, get in contact via atlas@eurac.eduWhich buildings are suitable for documentation?

Any building of historic and/or cultural value independent of the level of protection is considered - from medieval buildings over buildings from the 1920 s to post WWII architecture.

The information needed is structured in four categories

- images of the building and key figures of the intervention

- a description of the context and the rationale behind the solutions adopted

- the different retrofit solutions implemented

- evaluation of the intervention in terms of energy efficiency, internal climate, cost and environmental impact. 


\section{HIBERATLAS BEST PRACTICE EXAMPLE [LINK]}

\section{Ansitz Kofler - post retrofit monitoring best practice}

\begin{abstract}
The main building of "Ansitz Kofler" was built in 1749 and had in 1769 Wolfgang Amadeus Mozart as a guest. The Orangerie was added a bit later: as $30 \mathrm{~m}$ long and $5 \mathrm{~m}$ wide structure with spacious and bright rooms, used for breeding tropical fruits - for which the climate in Bozen, even if south of the Alps, would otherwise have been too harsh. In 1925 the Orangery was converted to a dwelling: the windows were scaled down, and internal walls were added, forming a suite of rooms aligned with each other (so called enfilade). As typical for buildings of this age in Bozen, the bearing structure is a stone masonry, with stones of different size, taken from the rivers in the area.
\end{abstract}

Reaching KlimaHaus A level $\left(<30 \mathrm{kWh} / \mathrm{m}^{2} \mathrm{a}\right)$ was voluntary and going far beyond usual practice. The retrofit project finally included a bundle of measures, which together allowed to reach the target of Klimahaus $A$. The $60 \mathrm{~cm}$ thick stone walls were insulated - from inside along the east facade and from outside at the west facade (where a portico resulted in clear aesthetic border to the remaining building) with large overlapping areas to avoid thermal bridges. Large passive house windows (with wooden frame) allow to reduce losses and optimise solar gains. The insulation of the floor was combined with providing the necessary space for technical installation and ducts and the ceiling towards the terrace was insulated from above, allowing to keep the existing wood boarding. A ventilation system with heat recovery and ground-air heat exchanger (to pre-heat the air in winter, and cool it in summer) further improved comfort and reduced the energy need, which finally is covered by a pellet boiler in a climate neutral way.

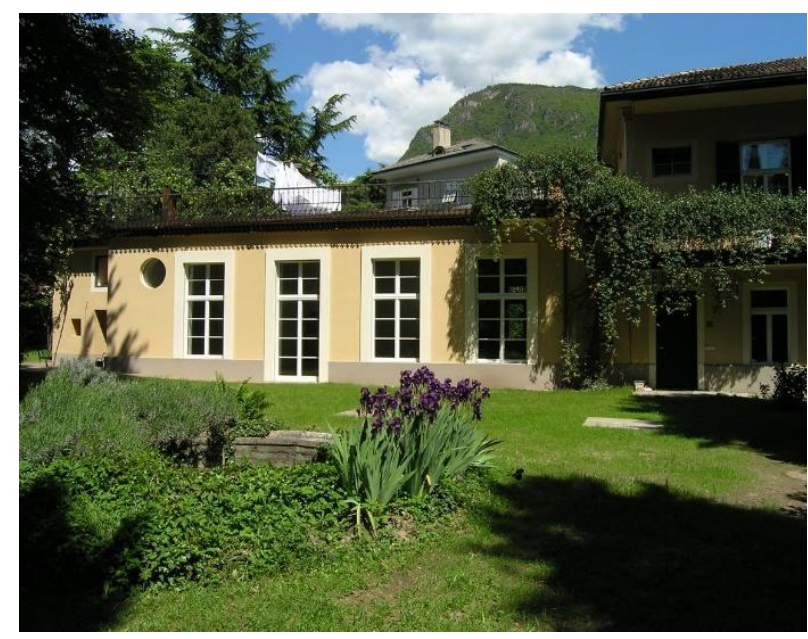

Ansitz Kofler, Bolzano, Italy.
The renovation conecpt was elaborated in close collaboration with the preservation office of South Tyrol: They supported the whish of the owner, to go back towards the architectural appearance of the Orangery. This approach would also connect the wing closer to the internal park, which is specifically part of the protection.

The building is unusally well monitored post retrofit. In both living room and bedroom temperature $(T)$ and relative humidity $(\mathrm{RH})$ are monitored. On the terrace temperature $(T)$, relative humidity $(R H)$, wind speed and solar radiation are monitored. Since solar radiation is measured precisely at Bolzano airport, but mountains might shadow the building in the old town differently, a simple solar radiation sensor was chosen, to mainly complement available data.

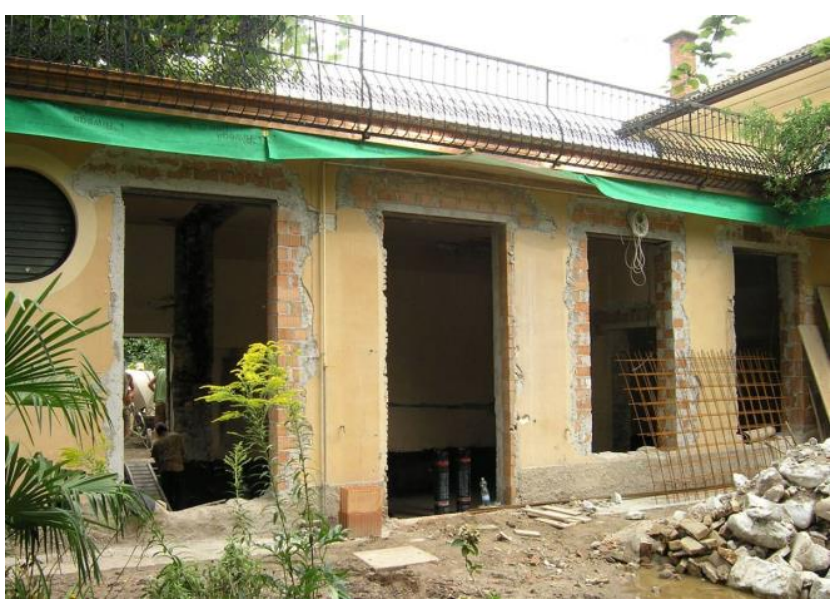

Ansitz Kofler during retrofit.

Also the insulated walls are monitored. Overall 4 wall profiles are monitored, each including (i) exterior surface $\mathrm{T}$, (ii) $\mathrm{T}$ and $\mathrm{RH}$ between stone wall and insulation, (iii) $\mathrm{T} \& \mathrm{RH}$ before the vapour barrier, (iv) T\&RH after the vapour barrier, (v) heat flux at the interior surface and (vi) interior surface $\mathrm{T}$. Furthermore the $\mathrm{T}$ at the connection from partition to outer wall is monitored - to quantify the thermal bridge effect. Finally, $\mathrm{T}$ and $\mathrm{RH}$ are measured in two wooden beams.

Monitoring results showed comfortable temperatures both in winter and summer. Monitored winter conditions ranged between $19^{\circ} \mathrm{C}$ and $21^{\circ} \mathrm{C}$, with the lower temperatures corresponding to periods where the user was absent. In summer, the operative temperatures ranged between $24^{\circ} \mathrm{C}$ and $27^{\circ} \mathrm{C}$ with outdoor daily averages going up to $29^{\circ} \mathrm{C}$. 


\subsection{Post-occupancy evaluation}

This is generally a weak point in the whole refurbishment process. Without proper evaluation, it is not possible to assess the impact of interventions, or to know if technical systems function the intended way. Furthermore, post-occupancy evaluation provides an opportunity to fine tune HVAC systems and have a dialogue with the people involved in the daily operation and use of the building.

\section{Success factors for post-occupancy} evaluation

$\checkmark$ A detailed plan for the evaluation is agreed on before the project starts

$\checkmark$ The evaluation is broad and includes many different aspects, including heritage

$\checkmark$ Lessons learned are identified, and communicated to future projects

The post-occupancy evaluation should follow procedures mandated by contracts and/or national legislation. However, there is often no mandatory procedure for refurbishment projects, only for new construction. For a historic building the evaluation should refer to the assessment categories used in the selection process described above (where relevant). EN 16883:2017 recommends a first evaluation after the implementation has been completed and a second evaluation within 1-3 years. 
Castaldo, V.L., Pisello, A.L., 2018. Uses of dynamic simulation to predict thermal-energy performance of buildings and districts: a review. Wiley Interdiscip. Rev. Energy Environ. $\quad 7, \quad 1-34$. https://doi.org/10.1002/wene.269

Conservation principles, policies and guidance - for the sustainable management of the historic environment, 2008. . Historic England.

Crawley, D.B., Hand, J.W., Kummert, M., Griffith, B.T., 2008. Contrasting the capabilities of building energy performance simulation programs. Build. Environ. 43, 661-673. https://doi.org/10.1016/j.buildenv.2006.10.0 27

Design Builder Software, n.d. Official web site [WWW Document].

URL http://www.designbuilderitalia.it/ (accessed 6.12.19).

EQUA, n.d. IDA ICE - Simulation Software, Official website [WWW Document]. URL https://www.equa.se/en/ida-ice (accessed 6.12.19).

Eriksson, P., Hermann, C., Hrabovszky-Horváth, S., Rodwell, D., 2014. EFFESUS Methodology for Assessing the Impacts of EnergyRelated Retrofit Measures on Heritage Significance. Hist. Environ. 5, 132-49. https://doi.org/10.1179/1756750514Z.0000 0000054

European Committee for Standardization, 2017. EN 16883:2017 Conservation of cultural heritage - Guidelines for improving the energy performance of historic buildings.

European Committee for Standardization, 2011. EN 15898:2011 Conservation of cultural property - Main general terms and definitions.

Fredheim, L.H., Khalaf, M., 2016. The significance of values: heritage value typologies reexamined. Int. J. Herit. Stud. https://doi.org/10.1080/13527258.2016.117 1247

Havinga, L., Colenbrander, B., Schellen, H., 2019a. Heritage significance and the identification of attributes to preserve in a sustainable refurbishment. J. Cult. Herit. https://doi.org/10.1016/J.CULHER.2019.08 .011

Havinga, L., Colenbrander, B., Schellen, H., $2019 \mathrm{~b}$. Heritage attributes of post-war housing in Amsterdam. Front. Archit. Res. 9, 1-19. https://doi.org/10.1016/j.foar.2019.04.002

Herrera-Avellanosa, D., Haas, F., Leijonhufvud, G., Brostrom, T., Buda, A., Pracchi, V., Webb, A., Hüttler, W., Troi, A., 2019. Deep renovation of historic buildings. Int. J. Build. Pathol. Adapt. 38. https://doi.org/10.1108/IJBPA-12-20180102

IES, n.d. Official website [WWW Document]. URL https://www.iesve.com/ (accessed 6.12.19).

Maile, T., Fischer, M., Bazjanac, V., 2007. Building Energy Performance Simulation Tools-a Life-Cycle and Interoperable Perspective.

Marquis-Kyle, P., Walker, M., 2004. The illustrated Burra charter Good practice for Heritage Places, 3rd ed. Australia ICOMOS.

Mason, R., 2002. Assessing values in conservation planning: Methodological issues and choices, Assessing the values of cultural heritage. The Getty Conservation Instittute.

National Park Service - US Department of the interior, Technical Preservation Services [WWW Document], n.d. . Preserv. Briefs 17 Archit. Character - Identifying Vis. Asp. Hist. Build. Aid Preserv. Their Character. URL https://www.nps.gov/tps/how-topreserve/briefs/17-architecturalcharacter.htm (accessed 5.15.20).

Pallin, S., Ph, D., Shrestha, S., Ph, D., Adams, M., 2017. State-of-the-Art for Hygrothermal Simulation Tools.

Schmidt, S., Lindauer, M., Hoppe, M., 2012. Comparing TRNSYS and WUFI ${ }^{\circledR}$ plus simulation models-illustrated on models validated on measurements at SchackGallery Munich, in: Proceedings of the 5th IBPC, Kyoto, Japan, May 28-31.

Schwab, M., 2004. Review of Building Energy Simulation Tools that Include Moisture Storage in Building Materials and HVAC 
Systems. Dep. Mech. Eng. Univ. Sask. 113.

Stiernon, D., Trachte, S., de Bouw, M., Dubois, S., Vanhellemont, Y., 2017. Heritage value combined with energy and sustainable retrofit: representative types of old Walloon dwellings built before 1914 . Energy Procedia 122, 643-648. https://doi.org/10.1016/J.EGYPRO.2017.07 .363

Sustainable Historic Towns: A Handbook about DIVE - Urban Heritage Analysis, 2010. Riksantikvaren Norway.

Tonnesen, A., 1997. InterSAVE - International Survey of Architecturel Values in the Environment. Ministry of Environment and Energy The National Forest and Nature Agency, Denmark, Copenhagen.

TRNSYS, n.d. Official website [WWW Document]. URL http://www.trnsys.com/ (accessed 6.12.19).

Webb, A., 2017. Energy retrofits in historic and traditional buildings: A review of problems and methods. Renew. Sustain. Energy Rev. 77, 748-759. https://doi.org/10.1016/j.rser.2017.01.145 